
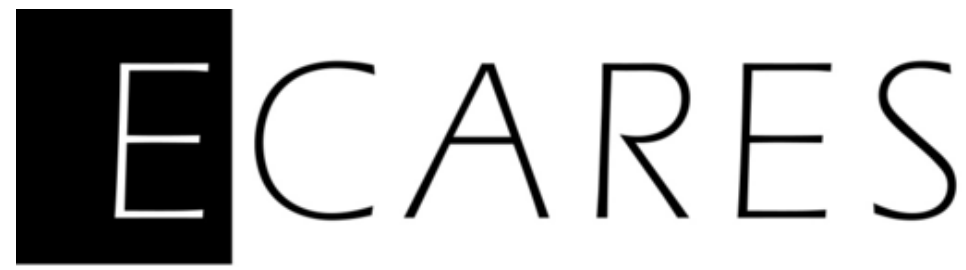

\title{
Identifying Financial Constraints
}

\author{
Laurens Cherchye \\ Katholieke Universiteit Leuven \\ Bram De Rock \\ SBS-EM, ECARES, Université libre de Bruxelles \\ Katholieke Universiteit Leuven \\ Annalisa Ferrando \\ European Central Bank \\ Klaas Mulier \\ Ghent University and National Bank of Belgium \\ Marijn Verschelde \\ IESEG School of Management, LEM (UMR-CNRS 9221) \\ Katholieke Universiteit Leuven
}

February 2020

ECARES working paper 2020-04

ECARES

ULB - CP 114/04

50, F.D. Roosevelt Ave., B-1050 Brussels BELGIUM

www.ecares.org 


\title{
Identifying Financial Constraints*
}

\author{
Laurens Cherchye $^{\dagger} \quad$ Bram De Rock $^{\ddagger} \quad$ Annalisa Ferrando ${ }^{\S}$ \\ Klaas Mulierף Marijn Verschelde\|
}

February 6, 2020

\begin{abstract}
We propose a new methodology to recover firm-year level financial constraints from firms' production behavior. We model financial constraints as the profitability that firms forgo when budget constraints on input costs bind, impeding them from using the optimal level inputs and technology in the production process. We estimate and validate our measure using a unique dataset combining firms' balance sheets from 2005 to 2015 in five Euro Area countries with survey information on firms' self-reported financial constraints, such as actual loan rejections or discouragement. Further, we show that our measure recovers the country-specific trends of financial constraints during the financial and sovereign debt crisis, and correlates only weakly with the three most popular indices of financial constraints.
\end{abstract}

Keywords: Financial constraints, identification, production function

JEL classification: E44, G00, G30, G32

* The authors would like to thank Çagatay Bircan, Olivier De Jonghe, Nico Dewaelheyns, Özlem Dursun-de Neef, David Martinez-Miera, Matthias Meier, Ramana Nanda, Steven Ongena, Angelos Theodorakopoulos, Silvio Vismara as well as seminar participants at Lille University, Tilburg University, the European Central Bank, the National Bank of Belgium, the 15th Corporate Finance Day, the 4th Benelux Banking Research Day, the Annual SAFE Conference, the 2nd CEPR Endless Summer Conference on Financial Intermediation and Corporate Finance, the 1st EBRD/ECB Compnet/IWHalle FINPRO conference for useful comments. Laurens Cherchye gratefully acknowledges the European Research Council (ERC) for his Consolidator Grant 614221. Bram De Rock gratefully acknowledges the FWO and FNRS for their support. The views expressed are solely those of the authors and do not necessarily represent the views of the European Central Bank or the National Bank of Belgium.

${ }^{\dagger}$ Katholieke Universiteit Leuven. e-mail: laurens.cherchye@kuleuven.be.

${ }_{\ddagger}^{\ddagger}$ ECARES, Université libre de Bruxelles and Katholieke Universiteit Leuven, e-mail: bram.de.rock@ulb.be.

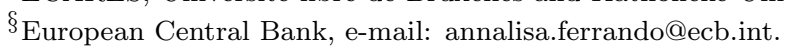

『Ghent University and National Bank of Belgium, e-mail: klaas.mulier@ugent.be.

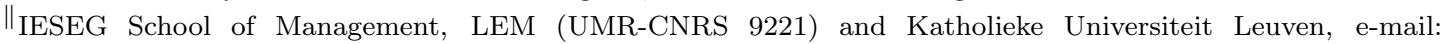
m.verschelde@ieseg.fr. 


\section{Introduction}

Financial constraints are often characterized as an inelastic supply of external finance, implying a constraint on firm decisions whenever internal financing is insufficient. The impact of these constraints is known to be quite significant. Chodorow-Reich (2014) and Amiti and Weinstein (2018), for instance, showed that credit supply shocks (which essentially make the supply of external finance more inelastic) explain between 30 and 50 percent of changes in aggregate employment and investment. Resolving financial constraints therefore remains a major policy concern. However, for policy interventions to be timely and effective, it is crucial to dispose of a measure that adequately tracks the level and evolution of financial constraints. Having such a measure is also highly relevant for academics as the adequacy of the financial constraints measure used (either as dependent or main independent variable) will have a large influence on the outcome and conclusions of our studies.

Unfortunately, recent research by Farre-Mensa and Ljungqvist (2016) shows that the measures of financial constraints that exist up to date in the literature do not adequately recover financial constraints. These measures, including popular indices developed by Kaplan and Zingales (1997), Whited and Wu (2006), and Hadlock and Pierce (2010), have in common that they are proxy variable approaches that try to measure financial constraints by a combination of observable characteristics. However, in practice, many unobservable characteristics (e.g. trust in management, customer dependence, investment opportunities, banks' lending standards, etc.) also play a very important role.

Our new measure. In this paper, we take an alternative approach by recovering financial constraints from the actual optimizing behavior of profit maximizing firms. We build our identification strategy on the findings that for homogeneous sets of 
firms, firm growth constraints have predominantly a financial nature (see e.g. Beck et al. (2005)). In our profit maximizing model, not operating at the optimal input level reveals that a firm faces a highly inelastic supply of external finance causing a binding constraint on input costs. Therefore, we recover financial constraints as the firm's foregone profitability due to binding input cost constraints that prohibit the firm from using the optimal level of inputs.

To construct our measure in a reliable and robust way, we follow a three-step procedure. In the first step, we estimate firm-year level unobserved productivity as the minimal levels of unobserved technology that are needed to "close-to" rationalize our data with profit maximization (see below for more details). To optimally avoid functional biases, we do this without specifying any parametric structure on the production process (as in Cherchye et al. (2018)). In the second step, we include these estimates - which can be seen as unobserved technological inputs in the production function- in the total input costs, together with the cost of tangible capital and the cost of labor. In this way, we control in a natural way for the endogenous choice of both observed inputs and unobserved productivity. This allows us to compute firm-year level profitability as total profit (including unobserved costs related to unobserved productivity) over revenues. In the final step, we then measure the foregone profitability as the difference between the firm's realized profitability and the median achievable profitability revealed by all firms in a narrowly defined comparison set that have a more expensive production process than the specific firm and that show higher profit metrics. ${ }^{1}$

Our methodology has a number of distinguishing features compared to existing methods and measures. First, our measure provides a comprehensive picture of financial

${ }^{1}$ Our method, based on using production data to reconstruct optimal behavior and comparing optimal to actual behavior, is similar in spirit to the recent work that investigates the impact of for instance misallocation (see e.g. Lenzu and Manaresi (2018) and Collard-Wexler and De Loecker (2019)). 
constraints by capturing them as constraints on the total cost of all observed inputs (and not only tangible fixed assets as in investment-based approaches). Financial constraints could imply a reduced availability of long-term financing which will likely affect firms' capital expenditures (Campello et al., 2010; Amiti and Weinstein, 2018). However, financial constraints could also imply a reduced availability of short-term financing inducing a lack of working capital for firms. This will affect firms' production decisions especially when cash from sales arrives later than the cash needed to pay the material input goods from suppliers (Almeida et al., 2018) or the wages of the employees (Greenwald and Stiglitz, 1988). The fact that our measure covers the totality of the firm's production decision is thus important. Indeed, depending on the substitutability or complementarity of the production inputs, one could otherwise get an incomplete or even incorrect picture.

Second, our measure focuses on the total access to external finance rather than on a particular type of external finance (e.g. access to bond financing proxied by having a credit rating, or access to bank financing using loan application data from credit registers). If a firm faces constraints from one provider of external finance (e.g. banks), but is able to offset this with additional funds from another provider (e.g. suppliers), then the net effect (on production/profitability) will be zero.

Third, our measure is agnostic about the source of the financial constraints that firms face. As such, we do not need to rely on a specific shock/source for identification (e.g. a banking crisis or firms' collateral availability). In fact, the source could even be unobservable to the econometrician (e.g. trust in management).

Fourth, in contrast to certain measures that require stock market information, our framework is broadly applicable to all firms (listed/unlisted, small/large), as it solely requires production data. ${ }^{2}$

$\overline{2}$ Production data has the advantage that it is more readily available than financial data, especially for smaller and unlisted firms, and more frequently available in a common format for different countries and years than survey data. 
A potential caveat of our nonparametric method to identify financial constraints is that it does not structure potential deviations from exactly profit maximizing behavior resulting from factor adjustment costs, statistical noise, non-optimizing behavior, etc. Therefore, our empirical analysis will focus on "close-to" rationalization instead of "full" rationalization (following Afriat (1972); Varian (1990)), which robustifies our empirical measure against such confounding factors. Our concept of "close-to" rationalization also mitigates the potential influence of market power heterogeneity. In this respect, our empirical application additionally includes a robustness exercise showing that our method also works well when only considering a subsample of firms with low market power (see also below).

To demonstrate the empirical usefulness of our approach, we measure firm-year level financial constraints for nearly 150,000 manufacturing firms in five Euro Area countries (Belgium, Germany, France, Italy, and Spain). We use detailed balance sheet and profit \& loss account information from Orbis Europe and have information from 2005 to 2015, totaling more than 725,000 observations. We match this balance sheet information with the responses of firms that participated in the Survey on Access to Finance of Enterprises (SAFE) conducted by the European Central Bank and the European Commission. The SAFE database includes information on whether firms faced rejections on actual applications for external financing, whether firms were discouraged to apply for external financing, or whether they had no need at all for external financing. ${ }^{3}$

Empirical validation. We perform a number of analyses to shed light on the informational content and usefulness of our new financial constraints measure. First of all, we show how our measure relates to observed differences across firms and show

${ }^{3}$ While the survey data is property of the ECB, we will make our firm-year specific financial constraints estimates and code publicly available after publication. 
the impact of the financial and sovereign debt crisis. When looking across firms, we find that our new financial constraints measure relates positively and significantly (statistically and economically) with the firms' self reported obstacles to access external finance. In our main setup, these obstacles are defined as firms that either applied for a given source and were rejected or firms that were discouraged to apply for that source despite their needs. We find this signficant relation for obstacles in accessing bank loans, credit lines, and trade credit, but not for (quasi-)equity. Interestingly, this positive relation holds even after controlling for a wide battery of observable characteristics known to be important for access to external finance. This indicates that our measure captures more information on financial constraints than merely the characteristics observable to the econometrician.

When looking over time, our measure indicates that, on average, financial constraints declined from 2005 to 2007 and skyrocketed in 2008 and 2009 after the onset of the global financial crisis. After a small decline in 2010, our measure shows that financial constraints increased further during the sovereign debt crisis to a maximum in 2012, after which our measure reveals a downward trend in financial constraints. Decomposing this information down to the country-level, we find that the global financial crisis, and especially the sovereign debt crisis, exacerbated financial constraints in Spain and Italy, compared to Belgium, Germany and France. All this empirical evidence validates our new measure by showing that it picks up the expected patterns across firms and time.

Next, we conduct three additional exercises to further analyze the adequacy of our measure. First, we try to falsify our measure and relate it to a number of non-financial constraints that firms face, such as lack of product demand, regulation and fierce competition. We find that our measure does not pick up any of these other obstacles that firms might face. Second, we test whether our proposed measure of financial 
constraints is driven by confounding influences from market power heterogeneity. In casu, we show the robustness of our results on a subset of firms considered to have negligible price setting power, based either on their own sectoral market share or on the concentration of the sector they operate in. Third, we observe that firms which our measure identifies as being financially constrained do indeed show behavior in the next period that is consistent with being financially constrained. That is, we find that these firms rely more intensively on credit from suppliers and grant less credit to customers, draw from their cash buffers, and invest significantly less in tangible fixed assets and employment. All this seems to indicate that our measure is indeed able to isolate the firms' financial constraints.

Finally, we compare our measure of financial constraints with the three most popular and widely used indices in the literature, that is, the Kaplan-Zingales (KZ), Whited$\mathrm{Wu}(\mathrm{WW})$ and Hadlock-Pierce (HP) indices. The correlation between our measure and the KZ-index is around 7 percent. The correlation with the WW-index is 31 percent and with the HP-index 26 percent. Given that Farre-Mensa and Ljungqvist (2016) showed the inadequacy of these measures, this low correlation is not necessarily worrisome for our measure of financial constraints. We then relate both our measure of financial constraints and these three popular measures to the firms' self reported financial constraints. These analyses reveal first of all that our measure remains significantly related to all dimensions of the self-reported measures even when the other three measures are included. Secondly, the popular indices seem to relate positively to some of the self-reported constraints, but none of them seems to capture all dimensions. Moreover, once control variables are included in the regressions, none of the popular indices are significant anymore, while our measure still is.

Related literature. Our paper contributes to the extant literature on financial constraints. One of the earliest approaches to measure financial constraints indirectly 
was to classify firms according to a characteristic based on information asymmetry (e.g. size, credit rating, or industrial group affiliation) or based on revealed financing needs (e.g. dividend payout). The virtue of these measures was demonstrated by the higher investment-cash flow sensitivity of firms classified as constrained (see for instance Fazzari et al. (1988); Hoshi et al. (1991) and Carpenter et al. (1994, 1998)). The validity of this approach was later heavily criticized, starting by Kaplan and Zingales (1997). These authors built a text-based measure of financial constraints derived from the CEO's financial statement that accompanies the annual income statement of 49 quoted firms, known as the KZ-index (Kaplan and Zingales, 1997; Lamont et al., 2001). Later, Whited and Wu (2006) constructed an index (WWindex) of financial constraints that is derived from an economic investment model. Hadlock and Pierce (2010) and Hoberg and Maksimovic (2014) have studied the content of these indices using larger and longer samples. Overall, their results suggest that most components of the KZ-index and WW-index do not (or no longer) relate to financial constraints, leading Hadlock and Pierce (2010) to propose an index based solely on size and age (HP-index). Buehlmaier and Whited (2018) use textual analysis of listed firms' $10-\mathrm{K}$ filings to construct a measure of equity constraints, debt constraints and general external finance constraints.

Recently, Farre-Mensa and Ljungqvist (2016) found that none of the above discussed proxy variable approaches accurately measure financial constraints. ${ }^{4}$ By proposing a production behavior based methodology as full-fledged alternative for recovering financial constraints, we provide an accurate picture of financial constraints. Our methodology does not only provide a counterfactual framework that does not require a priori parametric assumptions on the production process of firms, but also exhibits explanatory power beyond existing indicators of financial constraints.

\footnotetext{
4 The textual measures of Buehlmaier and Whited (2018) are not part of the analysis of Farre-Mensa and Ljungqvist as their work precedes that of Buehlmaier and Whited.
} 
Outline. The remainder of the text is structured as follows. In Section 2, we propose the methodology to recover financial constraints from firms' production behavior, while correcting for unobserved heterogeneity in productivity (and the implied simultaneity issue). In Section 3, we describe the data and discuss the empirical set-up. In Section 4, we validate our advocated methodology. In Section 5, we conclude.

\section{Methodology}

Our strategy to recover financial constraints is based on the actual production behavior of profit maximizing firms and therefore requires production function identification. Seminal work of Marschak and Andrews (1944) and Olley and Pakes (1996) shows that input choices of firms can depend on productivity, implying a simultaneity issue when this dependency is disregarded. Cherchye et al. (2018) proposed a full-fledged nonparametric method to identify production functions of cost minimizing firms that are characterized by unobserved heterogeneity in productivity. ${ }^{5}$ The method avoids functional specification bias by not imposing any nonverifiable parametric structure on the production technology. It also avoids the simultaneity bias in a natural way by including the unobserved productivity input directly in the optimization problem.

We follow Cherchye et al. (2018) by considering productivity as latent input costs that may be chosen endogenously and usually have a technological nature (e.g., intangibles, R\&D expenses). When information on input costs (including latent inputs) is complete, there is no unobserved heterogeneity in productivity. Conversely, incomplete information on input costs implies unobserved heterogeneity that may

${ }^{5}$ Essentially, Cherchye et al. (2018) extend the methodology for nonparametric production analysis of Afriat (1972), Hanoch and Rothschild (1972), Diewert and Parkan (1983) and Varian (1984) by introducing unobserved productivity that is endogenous to observed input choices. 
cause an endogeneity issue. In the current paper, we extend this framework of Cherchye et al. (2018) to the case of constrained profit maximization. This will allow us to nonparametrically identify financial constraints from the observed production behavior. In Section 2.1, we introduce our method to recover financial constraints from production data through an illustrative example. In Section 2.2, we formally discuss our structural measure of financial constraints. Section 2.3 discusses in more detail the practical implementation of our proposed measure of foregone profitability due to financial constraints.

\subsection{Production behavior and financial constraints}

Following the original ideas of Shephard (1974), McFadden (1978), Lee and Chambers (1986) and Färe et al. (1990), we model financial constraints as unobserved constraints on profit maximization. ${ }^{6}$ We identify financial constraints from the observed firms' production behavior, using the assumption that these constraints are potentially binding. Loosening these binding constraints is thus expected to raise firm profits.

Three preliminary remarks are in order. First, we follow the abovementioned papers by assuming that financial constraints are exogenous to the production behavior of the firms. This also makes that these constraints do not depend on the firms' unobserved productivity levels. Next, we model the firm's optimization problem as static rather than dynamic. Importantly, however, under intertemporal separability of the firm's objective function, static optimization is a necessary condition for dynamic optimization. ${ }^{7}$ Last, for the purpose of exposition, we will mainly focus on "full"

\footnotetext{
${ }^{6}$ More recently, Blancard et al. (2006) extended the methodology of Färe et al. (1990) to specifically distinguish between short run and long run credit constraints. To focus our discussion, we will not explicitly consider this distinction in the current paper, but a similar extension of our newly proposed method is fairly straightforward.

7 In the static optimization problem, intertemporal interdependence of input and output decisions
} 
rationalization (meaning that firms are exactly profit maximizing) when introducing our methodology. In Section 2.3 we discuss how we can include statistical noise, moderate adjustment costs and small deviations from optimizing behavior into our methodology by using the concept of "close-to" rationalization (meaning that firms are approximately profit maximizing).

Profit maximization under financial constraints. We assume a production setting with $M$ inputs and a single output. The empirical analyst can use the following sample of firm observations $S=\left\{\mathbf{W}_{i}, \mathbf{X}_{i}, P_{i}, Q_{i}\right\}_{i \in N}$, with $\mathbf{W}_{i} \in \mathbb{R}_{++}^{M}$ the observed input prices, $\mathbf{X}_{i} \in \mathbb{R}_{+}^{M}$ the observed input levels, $P_{i} \in \mathbb{R}_{++}$the observed output price, and $Q_{i} \in \mathbb{R}_{++}$the observed output level for every observation $i \in N$.

To sketch the basic intuition of our approach, we start by considering the simple setting in Figure 1(a), in which each firm uses a single observed input (i.e. $M=1$ ). The dataset $S$ contains four profit maximizing firm observations: $i, i^{\prime \prime}, i^{*}$ and $j$. We let $\Pi_{i}(\mathbf{X}, Q)=P_{i} Q-\mathbf{W}_{i} \mathbf{X}$ represent the profit for input-output combination $(\mathbf{X}, Q)$ evaluated at the prices of firm observation $i$. Finally, we assume that observation $i$ is constrained in that input costs above $C$ are not achievable, i.e. $\mathbf{W}_{i} \mathbf{X}_{i} \leq C$.

Clearly, if firm observation $i$ were unconstrained and the production plans $\left(\mathbf{X}_{i^{*}}, Q_{i^{*}}\right)$ and $\left(\mathbf{X}_{j}, Q_{j}\right)$ were technically feasible at $i$, then using the input levels $\mathbf{X}_{i^{*}}$ or $\mathbf{X}_{j}$ would imply a higher profit at the prices $\left(\mathbf{W}_{i}, P_{i}\right)$, i.e. $\Pi_{i}\left(\mathbf{X}_{i^{*}}, Q_{i^{*}}\right)$ and $\Pi_{i}\left(\mathbf{X}_{j}, Q_{j}\right)$ both exceed $\Pi_{i}\left(\mathbf{X}_{i}, Q_{i}\right)$. To formally capture the possibility of differences in technical feasibility between firm observations, we make the distinction between the input $\mathbf{X}$, which is observed by the empirical analyst and the firm, and the latent "productivity" input $\Omega$, which is observed by the firm but not by the empirical analyst. Stated

can then be accounted for by suitably pricing inputs and outputs over the consecutive time periods. 
differently, the dataset $S$ does not contain any information on this productivity term $\Omega$, but productivity does affect the firms' observed output and input choices. The production technology depends on both the observed input $\mathbf{X}$ and the latent input $\Omega$, which implies $Q=F(\mathbf{X}, \Omega)$. Figure $1(\mathrm{~b})$ shows that the production plan of firm observation $i$ is technically feasible, i.e. $Q_{i}=F\left(\mathbf{X}_{i}, \Omega_{i}\right)$. We include the notion of productivity into the firm's profit maximization problem by assuming that observation $i$ maximizes its profits over both the observed input $\mathbf{X}$ and the latent input $\Omega$, which defines the extended profit concept $\Pi_{i}^{+}(\mathbf{X}, \Omega, Q)=P_{i} Q-\mathbf{W}_{i} \mathbf{X}-\Omega=$ $\Pi_{i}(\mathbf{X}, Q)-\Omega$.

To introduce our strategy to identify financial constraints, let us first assume that the productivity input $\Omega_{i}$ of firm observation $i$ is given. For this productivity level, the production plans of observations $i^{\prime \prime}$ and $i^{*}$ would become feasible for $i$ if the input (cost) constraint $C$ were relaxed. More specifically, the production plan $\left(\mathbf{X}_{i^{*}}, Q_{i^{*}}\right)$ achieves a maximal profit $\Pi_{i}\left(\mathbf{X}_{i^{*}}, Q_{i^{*}}\right)$ for the given production function $F\left(\mathbf{X}_{i}, \Omega_{i}\right)$ and input-output prices $\left(\mathbf{W}_{i}, P_{i}\right)$. In our approach, we take it that firm observation $i$ reveals its financial constraint by its suboptimal input choice. In particular, as any choice of $\mathbf{X}$ between $\mathbf{X}_{i}$ and $\mathbf{X}_{i^{\prime \prime}}$ yields an output level $F\left(\mathbf{X}, \Omega_{i}\right)$ that corresponds to a higher profit than $\Pi_{i}\left(\mathbf{X}_{i}, Q_{i}\right)$, we identify that firm observation $i$ 's input cost is constrained by the upper bound $C=\mathbf{W}_{i} \mathbf{X}_{i}$.

In general $\Omega_{i}$ will not be given. We follow Cherchye et al. (2018) by modeling unobserved productivity variation in terms of a latent input $\Omega$ that can be chosen endogenously. By doing so, we can also include firm observation $j$ into our identification of the financial constraints that apply to firm observation $i$. More specifically, we use that producing the output $Q_{j}$ with the (observed) input $\mathbf{X}_{j}$ requires an (unobserved) productivity level $\Omega_{j}$ (i.e. $Q_{j}=F\left(\mathbf{X}_{j}, \Omega_{j}\right)$ ), with $\Omega_{j}>\Omega_{i}$. To further explain the intuition of our approach, let us assume that $\Pi_{i}^{+}\left(\mathbf{X}_{j}, \Omega_{j}, Q_{j}\right)>\Pi_{i}^{+}\left(\mathbf{X}_{i^{*}}, \Omega_{i^{*}}, Q_{i^{*}}\right)()>$ 
$\left.\Pi_{i}^{+}\left(\mathbf{X}_{i}, \Omega_{i}, Q_{i}\right)\right)$. Then, as before, we can identify that firm observation $i$ 's observed input cost cannot exceed $C$ and, under this restriction, the firm is (constrained) profit maximizing at $\left(\mathbf{X}_{i}, \Omega_{i}\right)$ instead of $\left(\mathbf{X}_{j}, \Omega_{j}\right)$. In Section 2.2, the difference between the profit levels $\Pi_{i}^{+}\left(\mathbf{X}_{j}, \Omega_{j}, Q_{j}\right)$ and $\Pi_{i}^{+}\left(\mathbf{X}_{i}, \Omega_{i}, Q_{i}\right)$ will constitute the starting base for our empirical measure $F C$ that quantifies foregone profits due to financial constraints.

Recovering unobserved productivity. It is clear from the above that to operationalize our empirical measure $F C$, we need to identify the level of the latent productivity input $\Omega$. To illustrate our nonparametric identification procedure, we add firm observation $k$ to our exemplary setting in Figure 1(c); for ease of exposition, we set $\Omega_{k}=\Omega_{j}$. Observation $k$ uses a less costly production process than observation $i$ in terms of observed inputs (i.e. $\mathbf{X}_{k}<\mathbf{X}_{i}$ ). As the financial constraint $C$ does not prevent $i$ from choosing the input $\mathbf{X}_{k}$, we can infer that $\Pi_{i}^{+}\left(\mathbf{X}_{i}, \Omega_{i}, Q_{i}\right) \geq \Pi_{i}^{+}\left(\mathbf{X}_{k}, \Omega_{k}, Q_{k}\right)$. As we discuss in more formal detail in Section 2.3 , we can use this type of arguments to recover the level of the productivity input $\Omega$ for each firm observation, hereby using profit maximization (under financial constraints) as our core identifying assumption.

\section{FIGURE 1 HERE}

Clearly, erroneously omitting latent productivity inputs can bias the estimated profit losses due to financial constraints in unpredictable ways. Moreover, foregone profit estimates that omit latent inputs are subject to a simultaneity issue originating from the dependency of observed input choices on unobserved technological features (see Marschak and Andrews (1944) and Olley and Pakes (1996)). The literature on the estimation and identification of production functions has paid considerable attention to developing techniques that address this dependency problem. Notable examples 
include Olley and Pakes (1996), Levinsohn and Petrin (2003), Wooldridge (2009) and, more recently, Ackerberg et al. (2015) and Gandhi et al. (2016). These existing approaches require a (semi)parametric specification of the production technology, implying a potential functional form misspecification bias. The approach of Cherchye et al. (2018) that we use in the current paper avoids imposing parametric structure on the technological production possibilities. It allows us to identify financial constraints in terms of foregone profit while explicitly including latent productivity inputs into the analysis.

Goodness-of-fit parameter. Our procedure assumes that all unobserved heterogeneity in production processes can be considered as (endogenous) productivity. However, a well-established literature has shown that moderate adjustment costs prevail and can hinder the firm to produce at their optimal scale size as considered from a static viewpoint (see e.g. Lucas (1967) and Hamermesh and Pfann (1996)). We do not explicitly structure potentially non-linear adjustment costs in our identification method. Still, our empirical analysis will account for the possible influence of adjustment costs in a non-structural way. As we explain in Section 2.3, we endogenize a goodness-of-fit parameter $\theta$ into our recovery of $\Omega$, and we also include this parameter into our method to identify financial constraints. A value of $\theta$ equal to one conforms to the assumption of exactly profit maximizing firms, while $\theta$-values above unity accommodate possible deviations from exact profit maximization. In our empirical application we will set $1.01 \leq \theta \leq 1.1$, which corresponds to "approximately" profit maximizing behavior. At this point, it is worth noting that Hall (2004) effectively documents that adjustment costs are generally low or moderate. ${ }^{8}$

\footnotetext{
${ }^{8}$ Sensitivity tests available upon request show that our main results hold when we include additional restrictions on capital. In particular, if we model capital as having very high adjustment costs, hindering the firm to use more capital, our measure still significantly correlates with the direct questions on financial constraints as included in the SAFE survey.
} 
Generally, the parameter $\theta$ captures not only moderate adjustment costs, but also other potential disturbances such as low levels of statistical noise and small deviations from optimizing behavior. Basically, using this goodness-of-fit parameter makes that our identifying restrictions resulting from the profit maximization assumption become less stringent. Stated differently, we focus on "close-to" rationalization by allowing for moderate inconsistencies of the data with exactly optimizing behavior. ${ }^{9}$

\subsection{Structural identification of financial constraints}

We next formally discuss our structural measure of financial constraints. As explained above, we assume a production function $Q=F(\mathbf{X}, \Omega)$, i.e. we consider the latent productivity input $\Omega$ as an endogenous choice variable for the firm. The firm's problem is to maximize profits by optimally choosing its output and inputs, which comprise both the observed inputs and the latent input. Given our specific research question, we assume profit maximization subject to financial constraints pertaining to the observed inputs. Particularly, we assume that the observed input cost cannot exceed some predefined level $C$.

Our specific empirical set-up makes that we cannot explicitly model financial constraints related to the unobserved inputs. If we have no information on the unobserved input, as in the current set-up, it is empirically meaningless to impose restrictions on the associated costs. As such, this implies that we implicitly make the assumption that constraints on the unobserved inputs are sufficiently correlated with those on the observed inputs. An alternative approach would be to include extra information (e.g. R\&D investments) into the analysis that may be related to productivity differences captured by $\Omega$. This in turn would allow for trying to model

${ }^{9}$ See, for example, Afriat (1972) and Varian (1990) for alternative goodness-of-fit measures that have been used in nonparametric production analysis. 
the relation between financial constraints and productivity. We abstract from this in our current paper.

This gives the following optimization problem:

$$
(O P) \quad \max _{\mathbf{X}, \Omega} P F(\mathbf{X}, \Omega)-\mathbf{W X}-\Omega \text { s.t. } \mathbf{W X} \leq C .
$$

Checking consistency with this optimization problem requires identifying the unknown production technology $F$ of the firm, the latent productivity input $\Omega$ and the budget constraint $C$. Throughout, we will assume that all input-output combinations with observed cost below $C$ (for the given prices $\mathbf{W}$ ) are feasible under the prevailing financial constraints. This implies that we abstract from frictions related to downsizing.

Financial constraints as foregone profitability. To facilitate comparison across firms, we use profitability (i.e., profit over revenues) as our metric of firms' profits. A convenient by-product is that profit differences are naturally scaled when computing foregone profits due to financial constraints. ${ }^{10}$

Assume that a firm observation $j$ achieves a higher profit than the firm observation $i$ at the prices $\left(\mathbf{W}_{i}, P_{i}\right)$ that apply to $i$. When computing the associated foregone profitability due to financial constraints, which we use as our measure of financial constraints $F C$, it is important to effectively account for the possibility of unobserved heterogeneity in productivity. Particularly, if there were no unobserved heterogeneity (i.e. complete information on the input costs), our financial constraint measure would

\footnotetext{
${ }^{10}$ We remark that our methodology is actually fairly straightforwardly adapted to alternative profit measures if deemed desirable.
} 
be defined as

$$
F C_{i}^{* *}=\frac{P_{i} Q_{j}-\mathbf{W}_{i} \mathbf{X}_{j}}{P_{i} Q_{j}}-\frac{P_{i} Q_{i}-\mathbf{W}_{i} \mathbf{X}_{i}}{P_{i} Q_{i}}=\frac{\Pi_{i}\left(\mathbf{X}_{j}, \mathbf{Q}_{j}\right)}{P_{i} Q_{j}}-\frac{\Pi_{i}\left(\mathbf{X}_{i}, \mathbf{Q}_{i}\right)}{P_{i} Q_{i}} .
$$

By contrast, when inputs are only partially observed, we can account for heterogeneity in productivity by explicitly including latent input in the analysis. This obtains the alternative financial constraint measure

$$
\begin{aligned}
F C_{i}^{*}= & \frac{P_{i} Q_{j}-\mathbf{W}_{i} \mathbf{X}_{j}-\Omega_{j}}{P_{i} Q_{j}}-\frac{P_{i} Q_{i}-\mathbf{W}_{i} \mathbf{X}_{i}-\Omega_{i}}{P_{i} Q_{i}} \\
& =\frac{\Pi_{i}^{+}\left(\mathbf{X}_{j}, \Omega_{j}, Q_{j}\right)}{P_{i} Q_{j}}-\frac{\Pi_{i}^{+}\left(\mathbf{X}_{i}, \Omega_{i}, Q_{i}\right)}{P_{i} Q_{i}} .
\end{aligned}
$$

Following our discussion in Section 2.1, there is no reason to suspect that $F C_{i}^{* *}$ equals $F C_{i}^{*}$, resulting in an omitted variable bias when unobserved input costs are disregarded. In our practical application, we can compute the measure $F C_{i}^{*}$ by using our nonparametric estimates of the latent productivity inputs $\Omega$.

Measuring financial constraints. Relaxing financial constraints opens the door for additional production possibilities, leading to higher profitability. To empirically measure foregone profitability due to prevailing financial constraints, we compare actual profitability with an estimate of achievable profitability under less stringent financial constraints.

For each firm observation $i$, we estimate achievable profitability as the median profitability (evaluated at the given prices $\mathbf{W}_{i}$ and $P_{i}$ ) defined over all firm observations $j$ with observed cost, profitability and profit levels at least as high as those of $i$; we let $T_{i}^{\text {beyond }}$ to denote the set of such observations $j$ (see Section 2.3 for formal details). Intuitively, this provides an outlier-robust measure of expected profitability 
when loosening firm $i$ 's financial constraints. ${ }^{11}$ Then, we can define the following measure of foregone profit due to financial constraints:

$$
F C_{i}=\text { Median }_{j \in T_{i}^{\text {beyond }}}\left(\frac{P_{i} Q_{j}-\mathbf{W}_{i} \mathbf{X}_{j}-\Omega_{j}}{P_{i} Q_{j}}\right)-\frac{P_{i} Q_{i}-\mathbf{W}_{i} \mathbf{X}_{i}-\Omega_{i}}{P_{i} Q_{i}}
$$

Because the set $T_{i}^{\text {beyond }}$ only contains firm observations $j$ with at least the same profitability level as the evaluated observation $i$, our $F C$ measure is bounded from below by zero. Higher values generally reveal more profit loss caused by financial constraints.

\subsection{Operationalizing the identification of productivity and financial constraints}

To conclude this section, we present the testable implications that our data set $S$ needs to satisfy to be consistent with the above structural model. Building on these testable implications, our nonparametric methodology can be operationalized by solving simple linear programming problems. Particularly, we can use linear programming to estimate the latent inputs $\Omega$ in noisy settings (where using the goodness-of-fit parameter $\theta$ accounts for adjustment costs, statistical noise and deviations from optimizing behavior, as explained above). The obtained latent input estimates $\hat{\Omega}$ serve as input for the operationalization of the financial constraints estimation.

Definitions and characterization. We first define (OP)-rationalizability of the dataset $S$ under financial constraints:

\footnotetext{
${ }^{11}$ While we here choose to focus on median profitability to define our outlier-robust metric of foregone profit, we may of course also use other summary statistics when deemed more desirable (such as the mean, maximum or some other quantile of the profitability distribution).
} 
Definition 1. The dataset $S=\left\{\mathbf{W}_{i}, \mathbf{X}_{i}, P_{i}, Q_{i}\right\}_{i \in N}$ is (OP)-rationalizable under financial constraints $C_{i}$ if there exist latent input levels $\Omega_{i}$ and a production function $F$ such that, for all firm observations $i \in N$,

$$
\left(\mathbf{X}_{i}, \Omega_{i}\right) \in \arg \max _{\mathbf{X}, \Omega} P_{i} Q_{i}-\mathbf{W}_{i} \mathbf{X}_{i}-\Omega_{i} \text { s.t. } \mathbf{W}_{i} \mathbf{X} \leq C_{i} .
$$

From Theorem 3 of Varian (1984), we can define the following testable implications for (OP)-rationalizability of a given dataset $S .^{12}$

Proposition 1. Let $S=\left\{\mathbf{W}_{i}, \mathbf{X}_{i}, P_{i}, Q_{i}\right\}_{i \in N}$. The following statements are equivalent:

(i) The dataset $S$ is (OP)-rationalizable under financial constraints $C_{i}$;

(ii) There exist latent input numbers $\left\{\Omega_{i}\right\}_{i \in N}>0$ that satisfy, for all $i \in N$ and $j$ in $\boldsymbol{T}_{i}^{F C}=\left\{j \mid C_{i} \geq \mathbf{W}_{i} \mathbf{X}_{j}\right\}$, the inequalities

$$
P_{i} Q_{i}-\mathbf{W}_{i} \mathbf{X}_{i}-\Omega_{i} \geq P_{i} Q_{j}-\mathbf{W}_{i} \mathbf{X}_{j}-\Omega_{j}
$$

Operationalization. We can use linear programming to check our testable conditions for (OP)-rationalization under financial constraints. Particularly, our linear programming problem below minimizes the share of unobserved costs in total costs subject to the rationalizability constraints in condition (ii) of Proposition 1.

To operationalize these conditions for each firm observation $i \in N$, we need to empirically approximate the set $\boldsymbol{T}_{i}^{F C}$. Here, we use that firm $i$ 's observed cost $\mathbf{W}_{i} \mathbf{X}_{i} \leq C_{i}$.

\footnotetext{
${ }^{12}$ Theorem 3 of Varian (1984) did not explicitly consider financial constraints or latent input. However, these extensions of Varian's original result are fairly straightforward and, therefore, we do not include an explicit proof.
} 
Then, we can define the set $\hat{\boldsymbol{T}}_{i}^{F C}=\left\{j \mid \mathbf{W}_{i} \mathbf{X}_{i} \geq \mathbf{W}_{i} \mathbf{X}_{j}\right\}$, which contains all firm observations $j$ with associated cost $\mathbf{W}_{i} \mathbf{X}_{j} \leq \mathbf{W}_{i} \mathbf{X}_{i}$. By construction we have that $\hat{\boldsymbol{T}}_{i}^{F C} \subseteq \boldsymbol{T}_{i}^{F C}$ and thus by setting $C_{i}$ equal to $\mathbf{W}_{i} \mathbf{X}_{i}$ we obtain an inner bound approximation.

To control for heterogeneity that cannot be considered as latent productivity input (e.g., due to adjustment costs, statistical noise or non-optimizing behavior; see our discussion in Section 2.1), we account for (small) deviations from "exactly" optimizing behavior in practice by using a goodness-of-fit parameter $\theta .{ }^{13}$ Basically, it weakens the original rationalizability requirement in Proposition 1 by increasing the left hand sides of the inequality constraints in condition (ii). Using this goodnessof-fit parameter considers "close-to" (instead of "exactly") (OP)-rationalizable firm behavior.

Taken together, we obtain the following linear program:

$$
\begin{gathered}
\min _{\Omega_{i} \in \mathbb{R}_{+}} \sum_{i} \frac{\Omega_{i}}{\mathbf{W}_{i} \mathbf{X}_{i}+\Omega_{i}} \\
\text { s.t. } \\
\forall i \in\{1, \ldots, N\}: \theta P_{i} Q_{i}-\mathbf{W}_{i} \mathbf{X}_{i}-\Omega_{i} \geq P_{i} Q_{j}-\mathbf{W}_{i} \mathbf{X}_{j}-\Omega_{j} \text { for all } j \in \hat{\boldsymbol{T}}_{i}^{F C}, \\
\text { with } \hat{\boldsymbol{T}}_{i}^{F C}=\left\{j \mid \mathbf{W}_{i} \mathbf{X}_{i} \geq \mathbf{W}_{i} \mathbf{X}_{j}\right\} .
\end{gathered}
$$

\footnotetext{
${ }^{13}$ We may need to account for such deviations in practice as observed firm behavior may effectively fail the "exact" rationalizability condition in Proposition 1. Specifically, assume that, for some $j$ and $i, P_{i} Q_{i}-\mathbf{W}_{i} \mathbf{X}_{i}<P_{i} Q_{j}-\mathbf{W}_{i} \mathbf{X}_{j}$ and $P_{j} Q_{j}-\mathbf{W}_{j} \mathbf{X}_{j}<P_{j} Q_{i}-\mathbf{W}_{j} \mathbf{X}_{i}$. Then, we must have $\Omega_{j}>\Omega_{i}$ (because of the first inequality) and $\Omega_{i}>\Omega_{j}$ (because of the second inequality), which is infeasible. Actually, we can give this infeasibility an intuitive interpretation. The two inequalities above imply that both firm observation $j$ and firm observation $i$ turn out to be profit inefficient when compared to each other (under their respective prices). Clearly, we cannot rationalize such behavior as profit efficient with a single dimension of heterogeneity in production (i.e. a single latent input). From all this, it is clear that infeasibilities will occur only for severe violations of profit maximization (when ignoring heterogeneity in productivity).
} 
This program obtains estimates of the unobserved $\Omega_{i}$ that we will use in our practical implementation. We use the minimal value of $\theta$ within the interval $[1.01,1.1]$ that makes the problem feasible. To do so, we apply a binary search routine to minimize the non-linear objective given the linear constraints. See Cherchye et al. (2018) for details.

Next, to operationalize the financial constraints estimation, we use the estimated $\hat{\Omega}_{i}$ in (3) and define the set of observations $\boldsymbol{T}_{i}^{\text {beyond }}$ as:

$$
\begin{gathered}
\boldsymbol{T}_{i}^{\text {beyond }}=\left\{j \mid \mathbf{W}_{i} \mathbf{X}_{i} \leq \mathbf{W}_{i} \mathbf{X}_{j}\right. \\
\text { and } \frac{P_{i} Q_{j}-\mathbf{W}_{i} \mathbf{X}_{j}-\hat{\Omega}_{j}}{P_{i} Q_{j}}>\frac{\theta P_{i} Q_{i}-\mathbf{W}_{i} \mathbf{X}_{i}-\hat{\Omega}_{i}}{P_{i} Q_{i}} \\
\text { and } \left.P_{i} Q_{j}-\mathbf{W}_{i} \mathbf{X}_{j}-\hat{\Omega}_{j}>\theta P_{i} Q_{i}-\mathbf{W}_{i} \mathbf{X}_{i}-\hat{\Omega}_{i}\right\}
\end{gathered}
$$

We thus consider the set of comparison partners with more observed costs that would violate the linear constraints as implemented in the linear program. As indicated above, we restrict the set of comparison partners to the subset of firm observations $j$ with at least the same profitability and profit levels as observation $i$, which makes that our $F C$ measure is bounded from below by zero.

\section{Application set-up and data construction}

The dataset is compiled by the European Central Bank and Bureau van Dijk. It augments detailed balance sheet and profit \& loss information available in Orbis Europe between 2005-2015 with the responses of firms that participated in the Survey on the Access to Finance of Enterprises (SAFE). The survey data is available from the 3rd wave of the survey (Q2-Q3 2010) until the 14th wave (Q4 2015-Q1 2016) for 
on average 6,500 firms in each wave, of which 90 percent are SMEs. Bureau van Dijk is not able to match every firm in SAFE with their balance sheet, but the matching is quite high (on average around $80 \%$, with variation across countries and sectors).

From this dataset, we exclude all non-manufacturing firms and further limit our sample to firms operating in the five largest Euro area economies: Germany, France, Italy, Spain, and Belgium. ${ }^{14,15}$ This combined dataset has the advantage that it allows us to construct our new financial constraints measure $(F C)$ from the production data included in Orbis Europe and subsequently validate its content with direct questions on financial constraints such as loan application outcomes included in the SAFE survey. Merlevede et al. (2015) show that production data originating from Orbis (using multiple version as we do) adequately approximates the entire economic activity of manufacturing firms in the selected countries as covered by the Structural Business Statistics database (SBS) provided by Eurostat. This greatly supports the external validity of our results.

\section{TABLES 1 and 2 HERE}

Table 1 shows how we define inputs, outputs and their prices. We include as output the deflated value added from sales. ${ }^{16}$ As inputs, we include the number of employees in full time equivalents (FTE) and deflated tangible fixed assets. Value added from sales differs from sales revenues in the sense that other operational costs and material input costs are already subtracted from sales revenues. Therefore we do not include material costs separately as input cost. ${ }^{17}$ For the output price, we use the

\footnotetext{
${ }^{14}$ The Netherlands is actually the fifth largest Euro area economy, but the coverage of firms in Orbis Europe is poor in the Netherlands. We replace the Netherlands by Belgium, which is the sixth largest Euro economy.

${ }^{15}$ See Appendix A for a detailed description of all data cleaning and estimation choices.

${ }^{16}$ We take value added from sales rather than sales revenue itself because there are no reporting requirements regarding the latter in Belgium and Germany, especially among smaller firms.

${ }^{17}$ However, in a robustness check excluding Belgium and Germany, we construct our measure using
} 
country-industry (nace 2-digit) level producer price deflator. For the input prices, we use respectively the price of labor (which is obtained by dividing total labor cost by the number of employees in FTE) and the country-industry (nace 2-digit) level deflator for gross fixed capital formation. Our country-industry (nace 2-digit) level deflators are based on EU KLEMS and Eurostat. To obtain homogeneous sets of firm observations as a basis of the $F C$ estimation, we only compare observations within countries in narrowly defined industry and firm size classes. We consider nace 4-digit industries (from the nace rev. 2 classification) and 7 firm size groups (roughly based on the European Commission firm size classification).

Furthermore, we only estimate $F C_{i t}$ (i.e. foregone profitability for firm $i$ in year $t$ ) when the number of observations in a country-sector-firm size group is equal to or more than 50. This selection criterion yields 3,143 country-sector-firm size groups with on average 986 comparison observations. We ran separate linear programs for all groups. As explained in Section 2.3, we further robustify our measure to influences from moderate adjustment costs, random noise and deviations from profit maximizing behavior by focusing on testable conditions for close-to rationalization. We do so by using a goodness-of-fit parameter $\theta$ that satisfies $1.01 \leq \theta \leq 1.1$. Cherchye et al. (2018) show in a Monte Carlo analysis that this value for the goodness-of-fit parameter ensures reliable nonparametric recovery of production function parameters and heterogeneity in productivity in settings with considerable noise. The average $\theta$ for our 3,143 linear programs is 1.04 .

In the final sample, we have all required balance sheet information for 149,391 firms that are observed on average 4,9 times between 2005 and 2015, implying a total number of 728,642 observations. 3,205 of these firms participated on average 2.1 times in the SAFE survey, implying a total number of 6,582 observations. The panel

deflated sales revenue as output measure and including deflated materials use in the observed costs. Baseline results using this measure are reported in Table 14 in Appendix B. 
component in the SAFE survey is thus rather weak, which limits the application of any analysis based on popular panel estimation techniques, such as (firm) fixed effects estimators.

\section{TABLE 3 HERE}

While the most popular measures of financial constraints are tailored towards listed firms, our measure uses production data which is in large-scale available for both listed and (usually smaller) non-listed firms. The vast majority of our sample is unlisted (99,7\%), including micro firms (22\%), small firms (46\%), medium sized firms $(20 \%)$ and large firms $(12 \%)$. On average, the number of employees in FTE is 76.32, ranging from 5 to more than 100,000. In addition, our dataset covers both starting and well-established firms, with firm age covering the range between 1 and 176. The sample is composed of 24.8 percent young firms (age lower or equal than 10), 42.7 percent mature firms (age higher than 10 and lower or equal than 25) and 32.5 percent old firms (age higher than 25).

We find that financial constraints -measured as foregone profitability- is on average 0.552, meaning that we estimate firms to have a profitability loss due to financial constraints of 55.2 percentage points of their value added. For half of the observations, profitability losses are estimated to exceed 39.7 percentage points. While this value may seem large at first sight, it is actually fairly moderate. Firstly, value added (as we define it) typically corresponds to about one third of total sales in terms of magnitude. This implies that one needs to scale our numbers by a factor of three to interpret it as a foregone profit margin. Secondly, our sample predominantly covers the global financial and sovereign debt crisis - a period known for high

financial constraints- and many observations come from firms in countries that were hit severely by these events. For 10.6 percent of observations, our estimates show no foregone profitability due to binding financial constraints, indicating that moving 
towards more costly production processes is not expected to increase profitability for these firm observations. Financial constraints, furthermore, seem to be quite persistent. The Spearman correlation with a one-year lag is 0.74 .

Our FC estimates, as summarized in Table 4, confirm the stylized fact that financial constraints are heterogeneous across firms and that this heterogeneity is related to firm characteristics. In particular, we confirm that smaller and younger firms are more likely to face financial constraints. The average $F C$ for micro firms amounts to 59.6 , which is 20 percentage points higher than the average $F C$ of medium sized and 12 percentage points higher than the average $F C$ of large firms. In line with Hadlock and Pierce (2010), the relationship between firm size and our measure of financial constraints thus seems to be U-shaped. Young firms face on average 9 percentage points higher $F C$ than mature firms and 17 percentage points higher $F C$ than old firms. Comparison across countries should be considered with care due to differences in sample composition. Still, we can conclude that financial constraints are overall higher in Spain and Italy (and remarkably also France). In these countries, they also exhibit a stronger relation with firm size and age. ${ }^{18}$ Last, our results (available upon request) show that financial constraints of private firms are on average 19.6 percent higher than the financial constraints of publicly listed companies.

\section{TABLE 4 HERE}

Next to the characteristics of financial constraints, we also find a robust relation between firm size and firm age on the one hand and the log of latent input on the

\footnotetext{
${ }^{18}$ Note that a comparison of the average levels of financial constraints across countries is difficult, as the sample composition is different. Further, our advocated measure of foregone profitability due to financial constraints relates to the influence of financial obstacles on both technology choice and profitability. This implies that our measure takes into account the severity of the missed opportunities in a natural way. As such, for France, the high average level of $F C$ may be the result of both higher levels and more heterogeneity in latent input. As sample composition within a country remains quite stable, analyzing the trend within countries does not require this caution.
} 
other hand. Summary statistics show that large firms overall have higher levels of the latent input. As discussed above, latent inputs can be interpreted as unobserved productivity. Our fully nonparametric estimates thus confirm the well-established positive correlation between measured productivity and firm size (see for instance Haltiwanger et al. (1999); Van Biesebroeck (2005); Forlani et al. (2016)).

\section{Empirical validation}

We next investigate to what extent our new measure indeed captures the degree of financial constraints of firms by designing exercises that look at several dimensions of our measure of financial constraints. First, we use our data to show that our measure correlates in the expected way with direct indicators of financial constraints, such as loan application outcomes, and with variables that are believed to be determinants of financial constraints, such as size and age. Somewhat related to this, we also use our measure to recover the influences of macro-economic events such as the '07-'08 crisis and the sovereign debt crisis. Again this will demonstrate that our measure recovers intuitive patterns.

To further validate our measure, we subsequently show that it does not pick up other non-financial constraints (e.g. slacking product demand or regulation). We also verify that the firms that we identify as being financially constrained are indeed behaving as financially constrained firms (e.g draw from cash buffers, use more supplier credit/grant less customer credit, etc.). Finally, we show that our measure is only moderately correlated with the main existing alternative measures of financial constraints. This shows that our measure can potentially be used to address the concerns raised by Farre-Mensa and Ljungqvist (2016) that we discussed above. 


\subsection{Self-reported measures of financial constraints}

We begin by testing whether our measure correlates with five direct measures of financial constraints as reported by firms in the SAFE survey. To shed light on this, we run a logit regression to correlate the different survey based measures of financial constraints to our measure of financial constraints $(F C)$, with and without control variables and various fixed effects:

$$
Y_{i, c, s, t}=g\left(\alpha F C_{i, c, s, t}, \beta X_{i, c, s, t-1}, \mu_{c}, \lambda_{s}, \nu_{t}, u_{i, c, s, t}\right)
$$

where $Y_{i, c, s, t}$ represents five different survey-based measures of financial constraints, with subscript $i$ indicating firm, $c$ indicating country, $s$ indicating sector at the nace 4-digit level, and $t$ indicating year. $g(\cdot)$ represents a logit function with components included in an additive manner. The first indicator concerns a dummy equal to 1 when a firm perceives Access to Finance to be its most pressing problem and 0 otherwise. The other four dummies concern Rejection or Discouragement, related to (a) Bank Loans, (b) Credit Lines, (c) Trade Credit, (d) Other Financing. These indicators take the value 1 when a firm was either (i) discouraged to apply for this source of external financing out of fear of rejection, (ii) when a firm applied for it but was rejected, or (iii) when a firm applied for it but had to refuse the offer because the borrowing costs were too high; and 0 when a firm applied for this source of external financing and got approved (see Table 1 for a detailed explanation of the dummies and Table 3 for summary statistics). $F C_{i, c, s, t}$ is our new financial constraints

measure. $X_{i, c, s, t-1}$ is a vector containing lagged variables that are typically believed to be determinants of financial constraints, such as the firms' financial pressure (i.e. the inverse of the interest coverage ratio), leverage, size, and age. The model further includes country fixed effects $\mu_{c}$, nace 4-digit sector fixed effects $\lambda_{s}$ and year fixed effects $\nu_{t} \cdot u_{i, c, s, t}$ captures random noise. 


\section{TABLE 5: HERE}

The results of the logit regressions are shown in Table 5 (marginal effects reported). All five survey based indicators show a statistically significant and strongly positive relation with our proposed $F C$ measure. The first column sheds light on the relation between our $F C$ measure and the probability that firms indicate that access to finance is their most pressing problem. Panel A indicates that a one standard deviation higher $F C$ relates to a 1.9 percentage point higher probability of perceiving access to finance as the most pressing problem, which is an increase of 15.1 percent relative to the average. After the inclusion of country, sector and year fixed effects in panel $\mathrm{B}$, the estimates show a 1.7 percentage point higher probability of perceiving access to finance as most pressing problem, equaling a 13 percent increase. Panel $\mathrm{C}$ shows that this association remains statistically significant when we include observed characteristics that determine financial constraints, but the size of the effect reduces to a 6.3 percent increase in the unconditional probability of perceiving access to finance as most pressing problem for a 1 standard deviation increase in our financial constraints measure.

Columns 2 to 5 of Table 5 show the relation between $F C$ and four indicators on external financing rejection or discouragement. All four indicators show a positive relation with FC, and all are significant except 'other financing' in column 5. This other financing refers, for instance, to equity, quasi equity, or crowdfunding. The relations in Columns 2 to 4 remain economically and statistically significant when we control for fixed effects at the country, sector and year level (Panel B) and when we further include observables that relate to financial constraints (Panel C). The results in Panel $\mathrm{C}$ indicate that our new measure captures more information on financial constraints than merely the observable characteristics.

In particular, the second column shows that our $F C$ measure relates positively to 
the firm's bank loan rejection or discouragement probability. One standard deviation higher financial constraints $(F C)$ is associated with a 6.5 percentage points higher probability of bank loan rejection or discouragement, which is a 26.4 percent increase (relative to the unconditional mean of 24.6 percent). After controlling for fixed effects and control variables, we still find a 6 percentage point higher probability, equaling to a 24 percent increase. Similar patterns arise for rejection or discouragement related to credit lines and trade credit. We respectively find that a one standard deviation higher $F C$ corresponds to respectively a 5.1 (credit line) and 5.2 (trade credit) percentage point higher probability of rejection or discouragement (after controlling for fixed effects and control variables), equaling to changes of over 15 percent relative to the unconditional average. In Table 13 in Appendix B, we show that these results hold when one drops the discouraged firms from the previous measures, hence only considering the rejection or approval of applications for external finance (columns 1 to 4 ), or when one adds to the previous measures also firms with no need for external financing due to sufficient internal financing available (columns 5 to 8). All in all, these results thus strongly support the idea that our FC measure - which solely requires production data - recovers a substantial part of the heterogeneity in financial constraints across observations at the firm-year level.

\subsection{Determinants of financial constraints}

A second test is whether our measure of financial constraints correlates with variables that are typically believed to be determinants of financial constraints. To this end, we run regressions on $Y_{i, c, s, t}$, representing six different measures of financial constraints. $X_{i, c, s, t-1}$ is a vector containing the same lagged variables that are typically considered to be determinants of financial constraints and we also include the same fixed effects. 


$$
Y_{i, c, s, t}=g\left(\beta X_{i, c, s, t-1}, \mu_{c}, \lambda_{s}, \nu_{t}, u_{i, c, s, t}\right) .
$$

In the first column, we use OLS to study how our new measure of financial constraints relates with the selected variables. In the last five columns of Table 6 we transform model (5) into a logistic regression model and look at how the five direct measures of financial constraints as reported by firms in the survey relate to the selected variables. $g(\cdot)$ then represents a logit function with additive components. Table 6 shows that our new measure of financial constraints $(F C)$ relates in the same way to observable (financial) characteristics that are typically believed to be determinants of financial constraints as the direct survey based indicators of financial constraints.

Our FC measure and the survey based measures show that firms that face higher financial pressure and have a higher leverage are overall more financially constrained. This is in line with what we expected since higher financial pressure implies that firms already need a large part of their earnings before interest and taxes to service their current financial debt, and thus have limited spare debt capacity. Firms with higher leverage are also more likely to face constraints on access to finance. First, a high leverage implies a low equity buffer, which could safeguard a firm from an unexpected negative shock. Second, a high leverage may also exacerbate agency conflicts between debt holders and shareholders. Further, Table 6 shows a negative relation between financial constraints and respectively firm age and firm size. As mentioned before, our FC measure provides a holistic picture of financial constraints. Indeed, we look at binding input cost constraints which can come from different frictions for different funding sources. Table 6 shows that the effect on size that we are picking up comes mainly from frictions in accessing bank loans and credit lines, while the effect on age comes mainly from frictions in accessing supplier credit. 
TABLE 6: HERE

\subsection{Macro-economic events}

Financial constraints might originate at the firm level (due to for instance insufficient equity or an underdeveloped business plan), but they might also originate at the macro-level. It has been shown for instance that firms report more financing obstacles in countries where the institutional development and the development of the banking sector is lower (Beck et al., 2006, 2007). Another example is the occurrence of a financial or a banking crisis, which both tend to amplify the financial constraints that firms face in an economy.

The global financial crisis of '07-'08 led to the insolvency of many (large) banks throughout Europe. To avoid a dramatic increase in the financial constraints of the firms in their country (i.e. to avoid a spill-over from the financial to the real sector), governments bailed out the failing banks. As these failing banks were often very large, bailing them out led to a huge increase in the outstanding government debt of many countries. In Spain and Italy, this led the financial markets to question the solvency of the sovereign. Unfortunately, as banks tend to hold significant amounts of sovereign debt, in particular of the domestic sovereign, the stress in the Spanish and Italian banking sector was not relieved after the bail-out of the failing banks as it kicked right back in once their respective sovereign became under stress. In this section we study whether our measure is able to pick up the impact of a macroeconomic event on the average level of financial constraints in an economy. The events that we consider are the financial crisis of '07-'08 and the sovereign debt crisis. As these events were exogenous to the non-financial firms in the countries in our sample, this is good validity test for our $F C$ measure. 
Figure 2 shows the evolution of $F C$ over the considered time period for all countries together. The figure shows the percentage differences with the average level in 2007 after filtering away influences from time-varying sample composition. These timevarying sample characteristics are filtered out by including the control variables in Panel $\mathrm{C}$ of Table 3 as well as firm fixed effects in a regression where our $F C$ measure is the dependent variable. This way, our variables of interest (i.e. the year fixed effects with 2007 as reference year) only pick up the part of $F C$ that is exogenous to the firms in the economy. We then scale them by the average level of $F C$ in 2007 for interpretational purposes.

Both the influence of the '07-'08 financial crisis and the sovereign debt crisis, which started in 2010 are well captured by our FC measure. Both our measure and the direct survey measure on Loan Rejection or Discouragement as documented in the SAFE survey show an inverse $U$ shape pattern of financial constraints in the period 2010-2015 with as peak 2012. ${ }^{19}$ The moderation of financial constraints from 2013 onward is in line with a calming of the credit markets after ECB president Mario Draghi's announcement of the "whatever-it-takes" policy to preserve the euro on July 26 th, 2012.

\section{FIGURE 2: HERE}

In Figure 3 we show the country-by-country equivalent of Figure 2. As one can see, the financial constraints increased after the onset of the global financial crisis by about 10 percent in Belgium, Germany and France, and about 20 percent in Italy and Spain. Furthermore, the previously documented increase of financial constraints during the sovereign debt crisis is entirely driven by Italy and Spain, consistent with the narrative that these countries were under scrutiny of the financial markets dur-

\footnotetext{
${ }^{19}$ As the sample size for SAFE survey measures is small, we can only compare general trends over all firms.
} 
ing the period 2011-2013, which was not the case for Belgium, Germany and France. Moreover, according to our measure, during the sovereign debt crisis, financial constraints increased more in Spain than in Italy. This is consistent with MFI data from the ECB on interest rates on new business loans. There, one can see that the reduced monetary policy rates after the onset of the financial crisis were well transmitted to the economy in Belgium, Germany, and France, but only poorly so in Italy, and even not at all in Spain.

FIGURE 3: HERE

\subsection{Non-financial constraints and price setting behavior}

One valid concern one might have about our new measure of financial constraints is whether we are not picking up other constraints firms might face (such as a drop in product demand for instance), rather than purely constraints of a financial nature. Indeed, our theoretical approach does not rule out this possibility. Note, though, that our identification strategy tries to mitigate this by estimating the foregone profitability through comparing firms within the same country, within the same nace 4-digit industry and within the same size group. As such, we ensure that comparison firms face, for instance, the same employment protection legislation and face similar product demand. Degryse et al. (2019) show that firms operating in the same industry, in the same location and that are of comparable size, also have a similar credit demand. The differences in the firms' chosen inputs (and associated profitability) are thus likely to pertain to the differences in the degree to which firms' credit needs have been met.

That being said, we try nevertheless to falsify the content of our measure empirically by verifying whether it correlates positively with a number of non-financial 
constraints that firms might face. We test whether our measure correlates positively with lack of product demand, fierce competition, too high costs of production or labor, insufficient availability of skilled employees, and too rigid regulation. The results of these tests (which are performed in a similar way as the tests in Table 5) are shown in Table 7 below. As can be seen, we find that our measure does not pick up any of these other obstacles that firms might face in a consistent and meaningful way, which strengthens our believe that our measure is indeed able to isolate the firms' financial constraints.

\section{TABLE 7: HERE}

A weakness of our current empirical set-up and analysis is that we use revenues (value added) -deflated using an industry-country-year specific deflator- as measure of the firm's output. As such, we cannot decompose revenues (value added) into (i) output price, (ii) output quality, (iii) output quantity, (iv) material input price, and (v) material input quantity. A well-established literature in industrial organization and international trade shows that all these aspects of revenues relate to firm size. As discussed in Syverson (2011), revenue based output measurement is desirable in the absence of quality or quantity information when quality differences are fully reflected in prices. When prices reflect market power differences, revenue based estimates of firm performance include influences of the competitive state of the local sector, making the concept of a.o. productivity less clear-cut and potentially biasing the empirical results. Our focus on close-to rationalization accommodates -at least to some extent- the potential impact of market power effects that yield deviations from exactly profit maximizing behavior as modeled above. To further test whether our proposed measure of financial constraints is driven by confounding influences from market power heterogeneity, we study the robustness of our results on a subset of firms considered to have negligible price setting power. For these firms, our output 
measure can be considered as a quality-adjusted quantity indicator.

To this end, we compute four measures of pricing power: the firm's domestic market share (nace 4-digit level), the firm's market share (nace 4-digit level, all 5 countries), the Herfindahl-Hirschman Index (HHI) for each domestic nace 4-digit sector, the HHI for each nace 4-digit sector (all 5 countries). We then re-run the analyses reported in Column 2 of Table 5, but exclude the top-quartile observations according to each of the four pricing power measures. The results are shown in Columns 2 to 5 of Table 8 , whereas Column 1 reproduces the full sample results of Column 2 in Table 5. As can be seen, the results for the subsamples where we believe the firms to have negligible pricing power are very similar to the full sample results. A Wald test confirms that the coefficients in Columns 2 to 5 are not statistically different from the ones in Column 1 in each of the panels. It is thus unlikely that our results would be biased or solely driven by pricing power.

\section{TABLE 8: HERE}

\subsection{The real effects of financial constraints}

In this section we aim to test whether we observe behavior of financially constrained firms that is consistent with being constrained. This may seem straightforward and too simplistic, but as Farre-Mensa and Ljungqvist (2016) show, this is not necessarily the case.

In contrast to Farre-Mensa and Ljungqvist (2016), we do not have an instrument at hand that exogenously changed the need for debt financing. We therefore resort to testing the relation of financial constraints with (a) firms' net trade credit position proxied either by days sales outstanding minus days payable outstanding (DSO 
- DPO) or by the (accounts receivable - accounts payable)/total assets ratio, (b) firms' cash management proxied by the growth of cash and cash equivalent or by the cash/total assets ratio, (c) firms' investment behavior proxied by growth of deflated tangible fixed assets (see Amiti and Weinstein (2018)), (d) firms' employment growth (see Chodorow-Reich (2014)). Ferrando and Mulier (2013) show that trade credit is used to manage firm growth by companies that face financial market imperfections. We expect firms that are more financially constrained to grant less credit to customers and to rely as much as possible on credit from suppliers (implying lower DSO minus DPO). Campello et al. (2010) show that financially constrained firms plan to draw more from their cash buffers than financially unconstrained firms during the financial crisis. The relation between financial constraints and input dynamics (c-d) is a direct consequence of input cost constraints, which we model in terms of foregone profitability.

We test the real effects of financial constraints, using the following empirical model:

$$
Y_{i, c, s, t}=\alpha F C_{i, c, s, t-1}+\beta X_{i, c, s, t-1}+\gamma_{i}+\mu_{c}+\lambda_{s}+\nu_{t}+u_{i, c, s, t} .
$$

Where $Y_{i, c, s, t}$ represents real effects (a)-(d) as discussed above. $F C_{i, c, s, t-s}$ is our lagged financial constraints measure. $X_{i, c, s, t-1}$ is a vector containing the respective lag of indicator (a)-(d) and lagged variables that are typically believed to be determinants of financial constraints, such as the firms' financial pressure, leverage, size, and age. The model further includes firm fixed effects $\gamma_{i}$, country fixed effects $\mu_{c}$, nace 4-digit sector fixed effects $\lambda_{s}$ and year fixed effects $\nu_{t} . u_{i, c, s, t}$ captures random noise.

In line with the idea that our advocated financial constraints measure $F C$ provides an accurate picture of financial constraints, Table 9 shows that higher financial constraints are related to lower net trade credit, a reduction in cash buffers, lower 
investment in fixed assets, and lower employment growth. These real effects of $F C$ are robust for the inclusion of firm fixed effects. Economically, we find a moderate, yet non-negligible effect. A one standard deviation increase in financial constraints is estimated to reduce the difference between days of credit granted to customers and credit taken from suppliers by 2.1 to 4.1 days, and decrease the size of accounts receivable on the balance sheet relative to the accounts payable on the balance sheet by 0.2 to 0.3 percent of total assets. Furthermore, a one standard deviation increase in financial constraints is estimated to reduce the firm's cash balances by 0.5 to 6.7 percent, and decrease the cash to asset ratio by 0.2 to 0.3 percent of total assets. Finally, a one standard deviation increase in financial constraints is estimated to decrease the log growth of tangible fixed assets by 1 to 1.5 percent and decrease employment growth with 0.5 to 1.5 percent.

\section{TABLE 9: HERE}

\subsection{Comparison with existing financial constraints indices}

In this final section we compare our measure of financial constraints with three existing and widely used measures of financial constraints: the Kaplan-Zingales (KZ) index, the Whited-Wu (WW) index, and the Hadlock-Pierce (HP) index. As these indices were built for publicly listed firms using stock market information, we cannot completely construct the indices for the private firms in our dataset (i.e. the majority). For these firms we will compute the indices based on the index components for which we do have the information available. However, we will also separately look at 1,902 firm-year observations from the 362 listed companies that are included in our dataset and for which we can completely construct the indices. 


\section{TABLE 10: HERE}

We first look at the Spearman rank correlations between our measure of financial constraints and the three indices, which are reported in Panel A (private firms) and Panel B (public firms) of Table 10. As can be seen, the correlations are rather low. The correlation between $F C$ and the KZ-index is around 7 percent for private firms and even less for public firms. The correlation for private (public) firms with the WW-index is 31 (27) percent and with the HP-index is 26 (13) percent. Given that Farre-Mensa and Ljungqvist (2016) showed the inadequacy of these existing measures, this low correlation is not necessarily worrisome for our measure of financial constraints, perhaps on the contrary. Although we are aware that a low correlation does not prove the adequacy of $F C$ as a measure of financial constraints, a high correlation would likely indicate it has the same flaws as the existing measures.

To improve our understanding of how our measure and the existing measures relate to each other and to the firms' self-reported financial constraints, we run the following regression analyses:

$$
Y_{i, c, s, t}=g\left(\alpha_{1} F C_{i, c, s, t}, \alpha_{2} K Z_{i, c, s, t}, \alpha_{3} W W_{i, c, s, t}, \alpha_{4} H P_{i, c, s, t}, \beta X_{i, c, s, t-1}, \mu_{c}, \lambda_{s}, \nu_{t}, u_{i, c, s, t}\right) .
$$

Where $Y_{i, c, s, t}$ represents again the five different survey-based measures of financial constraints as in Table 5. The first indicator concerns a dummy equal to 1 when a firm perceives Access to Finance to be its most pressing problem and 0 otherwise. The other four dummies concern Rejection or Discouragement, related to (a) Bank Loans, (b) Credit Lines, (c) Trade Credit, (d) Other Financing. We include the same determinants of financial constraints and fixed effects as before.

The results of these analyses are reported in Table 11 and reveal first of all that our $F C$ measure remains significantly related to all the same self-reported financial 
constraints dimensions as in the baseline analysis in Table 5, even when the other three measures are included as explanatory variables. Secondly, the popular indices seem to relate positively to some of the self-reported constraints. For instance, the KZ-index relates positively to the firms' perception that access to finance is the most pressing problem. The WW-index relates positively to firms perception that access to finance is the most pressing problem and to credit line rejections or discouragement. And the HP-index relates positively to both bank loan and trade credit rejections or discouragement. However, this implies that these indices fail to capture the other dimensions. Moreover, once control variables are included in the regressions, the popular indices no longer relate significantly to any of the self-reported financial constraints dimensions. The latter should not be surprising. Given that the three widely used indices are built solely using observables, their informational content becomes obsolete once we control for these observables. It is noteworthy to stress again that our FC measure captures both observable and unobservable drivers of financial constraints. The implication is that it indeed remains significantly related to self-reported financial constraints after controlling for observables, as can be seen in Panel C of Table 11.

A different way of showing the importance of capturing the unobservable determinants, is to look at the time-variation of the measures. Figure 4 shows the evolution of $F C$ over the considered time period for all countries together, for each of the three widely used indices. The figure shows the percentage differences with the average level in 2007 after filtering away influences from time-invariant sample composition. Note that here we only filter out time-invariant sample characteristics (i.e. firm fixed effects), as for the three indices the information over time can only come from the time-variation in the observables. We also add our $F C$ plot from Figure 2 to facilitate the comparison in the informational content of each of the measures. As can be seen, none of the three popular indices is capable of picking up the increase in 
financial constraints after the onset of the financial crisis or during the sovereign debt crisis. In fact, there is very little movement in the KZ-index over time, while the WW-index suggests that financial constraints decreased during the financial crisis, and the HP-index predicts a monotonic decrease in financial constraints over time, mainly because the average firm becomes larger and older over time (not due to inflation, as we use deflated total assets, or survivorship bias, as we have both exit and entry in the sample).

Finally, the low correlation between $F C$ and the popular measures that we report in Table 10 may mask offsetting high correlations with separate index components. To test for these potentially offsetting relations, we regress $F C$ on the index components for each index in Table 12. Panel A reports the impact of the five components of the Kaplan-Zingales index (Tobin's Q, long term book leverage (TLTD), cash flow $(\mathrm{CF})$, dividends (Div), cash holdings (Cash)). Panel B reports the impact of the six components of the Whited-Wu index (industry sales growth (ISG), sales growth (SG), long term book leverage, cash flow, dividends, size (in terms of total assets)). Panel $\mathrm{C}$ reports the impact of the three components of the Hadlock-Pierce index (size, size squared, age). In each of the panels, Columns 1 and 2 report results using the private firms in our sample and Columns 3 and 4 report results using the public firms in our sample.

First, there are two index components that relate to our $F C$ measure in the way predicted by the indices and do so for both private and public firms, namely cash flow and firm size (when linear). Second, some index components appear to relate significantly to our $F C$ measure in the way predicted by the indices for private firms, but not for public firms. For instance, long term book leverage is positively and significantly related to our $F C$ measure for private firms, while the opposite holds for public firms. Sales growth relates negatively and significantly to our $F C$ 
measure for private firms, but not for public firms. Dividends (which we can only compute for the public firms) and firm size (when non-linear) also belong in this list. The former is negatively related to our $F C$ measure, but is not significant. HP predicts a U-shaped effect of firm size. While this is indeed what we find for the private firms in our sample, we find an inverse U-shaped relation for the public firms. Third, some index components relate to our $F C$ measure in a way opposite to the one predicted by the indices. Cash is positively related to our $F C$ measure, particularly for the private firms in our sample. Tobin's Q (which we can only compute for the public firms) relates negatively to our $F C$ measure. Finally, industry sales growth is negatively instead of positively related with $F C$.

In sum, we find that the low correlations between our advocated financial constraints measure and popularly used measures go together with weak relations between our measure and sub-indicators of the alternative measures, especially for public firms.

Our index - with as distinguishing feature that it is not based on proxy variables - provides substantially different estimates of financial constraints in comparison to measures which were found to be inadequate. Stated differently, the use of a proper estimation methodology is essential for giving an adequate picture on the micro-dynamics of financial constraints.

\section{Conclusion}

Recently, Farre-Mensa and Ljungqvist (2016) argued for the need of new financial constraint measures as none of the five most popular measures (KZ-index, WWindex, HP-index, dividend payout and credit rating) accurately measure financial constraints. In this paper, we propose to recover financial constraints from production behavior. The basis of our identification strategy is the difference between the actual production behavior of profit maximizing firms and the optimal behavior de- 
rived from their comparison partners. In a fully nonparametric fashion, we detect foregone profitability as the difference between actual profitability and the profitability level we estimate to be achievable when financial constraints were less stringent. For this, we first solve a simultaneity issue that arises due to the dependency of observed input choices on usually unobserved heterogeneity in productivity.

We apply our methodology to detailed firm-year level balance sheet and profit \& loss information from Bureau van Dijk's Orbis Europe dataset for the period 20052015, which we linked with the Survey on Access to Finance of Enterprises (SAFE) as collected by the ECB at the firm level for the period 2010-2015. We cover five Euro area countries, which differ in terms of macro-events. An empirical validation of our advocated financial constraints measure shows that our indicator indeed has intriguing empirical bite. Our measure nicely picks up the financial constraints dynamics around the '07-'08 crisis and the sovereign debt crisis and relates strongly with direct survey measures of financial obstacles (e.g. loan rejections), even when we control for a wide battery of observable characteristics that are often presumed to relate to financial constraints. Further, our measure correlates as expected with well-recognized determinants of financial constraints and shows to correlate with dynamics related to firm growth and use of the trade credit channel. Overall, we show that we can recover a substantial part of the heterogeneity between firm-year observations in financial constraints with the sole use of widely available production data.

Our methodology has micro-economic foundations and provides an accurate picture of financial constraints. Still, further research is needed to obtain deeper insight into the heterogeneity across firms in how they are hindered by financial obstacles. We consider this paper as a starting ground for research on financial constraints that goes beyond partial indicators and makes direct use of the optimizing production behavior 
of firms. For instance, by adding (e.g. dynamic) structure to the methodology or by adding financial information, estimation can be tailored to the particular situation at hand and empirical identification of financial constraints could potentially be sharpened. 


\section{References}

Ackerberg, D., Caves, K., Frazer, G., 2015. Identification properties of recent production function estimators. Econometrica 83, 2411-2451.

Afriat, S., 1972. Efficiency estimation of production functions. International Economic Review 13, 568-598.

Almeida, H., Carvalho, D., Kim, T., 2018. Understanding the credit multiplier: The working capital channel .

Amiti, M., Weinstein, D., 2018. How much do bank shocks affect investment? Evidence from matched bank-firm loan data. Journal of Political Economy 126, $525-587$.

Beck, T., Demirgüç-Kunt, A., Maksimovic, V., 2005. Financial and legal constraints to growth: Does firm size matter? The Journal of Finance 60, 137-177.

Beck, T., Demirguc-Kunt, A., Laeven, L., Maksimovic, V., 2006. The determinants of financing obstacles. Journal of International Money and Finance 25, 932-952.

Beck, T., Demirguc-Kunt, A., Martinez Peria, M.S., 2007. Reaching out: Access to and use of banking services across countries. Journal of Financial Economics 85, $234-266$.

Blancard, S., Boussemart, J.P., Briec, W., Kerstens, K., 2006. Short- and long-run credit constraints in french agriculture: A directional distance function framework using expenditure-constrained profit functions. American Journal of Agricultural Economics 88, 351-364.

Buehlmaier, M., Whited, T., 2018. Are financial constraints priced? evidence from textual analysis. Review of Financial Studies . 
Campello, M., Graham, J.R., Harvey, C.R., 2010. The real effects of financial constraints: Evidence from a financial crisis. Journal of Financial Economics 97, 470-487.

Carpenter, R.E., Fazzari, S.M., Petersen, B.C., 1994. Inventory investment, internalfinance fluctuations, and the business-cycle. Brookings Papers on Economic Activity , 75-138.

Carpenter, R.E., Fazzari, S.M., Petersen, B.C., 1998. Financing constraints and inventory investment: A comparative study with high-frequency panel data. Review of Economics and Statistics 80, 513-519.

Cherchye, L., Demuynck, T., De Rock, B., Verschelde, M., 2018. Nonparametric production analysis with unobserved heterogeneity in productivity. KU Leuven, Department of Economics Discussion Paper Series 18.11.

Chodorow-Reich, G., 2014. The employment effects of credit market disruptions: Firm-level evidence from the 2008-09 financial crisis. Quarterly Journal of Economics 129, 1-59.

Collard-Wexler, A., De Loecker, J., 2019. (mis)allocation, market power, and global oil extraction. American Economic Review 104, 1568-1615.

Degryse, H., De Jonghe, O., Jakovljevic, S., Mulier, K., Schepens, G., 2019. Identifying Credit Supply Shocks with Bank-Firm Data: Methods and Applications. Journal of Financial Intermediation .

Diewert, W., Parkan, C., 1983. Linear programming tests of regularity conditions for production frontiers, in: Eichhorn, W., Henn, R., Neumann, K., Shephard, R. (Eds.), Quantitative Studies on Production and Prices. Physica-Verlag, Würzburg. 
Färe, R., Grosskopf, S., Lee, H., 1990. A nonparametric approach to expenditureconstrained profit maximization. American Journal of Agricultural Economics 72, $574-581$.

Farre-Mensa, J., Ljungqvist, A., 2016. Do measures of financial constraints measure financial constraints? The Review of Financial Studies 29, 271-308.

Fazzari, S., Hubbard, R., Petersen, B., 1988. Financing constraints and corporate investment. Brookings Papers on Economic Activity 1, 141-195.

Ferrando, A., Mulier, K., 2013. Do firms use the trade credit channel to manage growth? Journal of Banking \& Finance 37, 3035-3046.

Forlani, E., Martin, R., Mion, G., Muûls, M., 2016. Unraveling firms: Demand, productivity and markups heterogeneity. Technical Report 293. National Bank of Belgium Working Paper Series 293.

Gandhi, A., Navarro, S., Rivers, D., 2016. On the Identification of Production Functions: How Heterogeneous is Productivity? Working Paper. University of Western Ontario, Centre for Human Capital and Productivity (CHCP).

Greenwald, B., Stiglitz, J.E., 1988. Pareto inefficiency of market economies: search and efficiency wage models. .

Hadlock, C.J., Pierce, J., 2010. New evidence on measuring financial constraints: Moving beyond the KZ index. Review of Financial Studies 23(5), 1909-1940.

Hall, R.E., 2004. Measuring factor adjustment costs. The Quarterly Journal of Economics 119, 899-927.

Haltiwanger, J., Lane, J., Spletzer, J., 1999. Productivity differences across employers: The roles of employer size, age, and human capital. American Economic Review 89, 94-98. 
Hamermesh, D.S., Pfann, G.A., 1996. Adjustment costs in factor demand. Journal of Economic Literature 34, 1264-1292.

Hanoch, G., Rothschild, M., 1972. Testing assumptions of production theory: A nonparametric approach. Journal of Political Economy 80, 256-275.

Hoberg, G., Maksimovic, V., 2014. Redefining financial constraints: A text-based analysis. Review of Financial Studies 28, 1312-1352.

Hoshi, T., Kashyap, A., Scharfstein, D., 1991. Corporate structure, liquidity, and investment: Evidence from Japanese industrial groups. The Quarterly Journal of Economics 106(1), 33-60.

Kaplan, S.N., Zingales, L., 1997. Do financing constraints explain why investment is correlated with cash flow? Quarterly Journal of Economics 112, 169-216.

Lamont, O., Polk, C., Saa-Requejo, J., 2001. Financial constraints and stock returns. Review of Financial Studies 14(2), 529-554.

Lee, H., Chambers, R., 1986. Expenditure-constraints and profit maximization in U.S. agriculture. American Journal of Agricultural Economics 68, 857-865.

Lenzu, S., Manaresi, F., 2018. Sources and implications of resource misallocation: New evidence from firm-level marginal products and user costs. Working paper .

Levinsohn, J., Petrin, A., 2003. Estimating production functions using inputs to control for unobservables. Review of Economic Studies 70, 317-341.

Lucas, R.E.J., 1967. Adjustment costs and the theory of supply. Journal of Political Economy 75, 321-334.

Marschak, J., Andrews, W., 1944. Random simultaneous equations and the theory of production. Econometrica 12, 143-205. 
McFadden, D., 1978. Cost, revenue, and profit function, in: Fuss, M., McFadden, D. (Eds.), Production Economics: A Dual Approach to Theory and Applications. Amsterdam: North-Holland Publishing Co.

Merlevede, B., De Zwaan, M., Lenaerts, K., Purice, V., 2015. Multinational networks, domestic, and foreign firms in Europe. Ghent University Working Paper Series D/2015/7012/02.

Olley, G.S., Pakes, A., 1996. The dynamics of productivity in the telecommunications equipment industry. Econometrica 64, 1263-1297.

Shephard, R., 1974. Indirect production functions. Verlag Anton Hain, Meisenheim Am Glad.

Syverson, C., 2011. What determines productivity? Journal of Economic Literature 49, 326-365.

Van Biesebroeck, J., 2005. Firm size matters: Growth and productivity growth in African manufacturing. Economic Development and Cultural Change 53, 545-583.

Varian, H., 1984. The nonparametric approach to production analysis. Econometrica $52,579-598$.

Varian, H., 1990. Goodness-of-fit in optimizing models. Journal of Econometrics 46, $125-140$.

Whited, T.M., Wu, G., 2006. Financial constraints risk. Review of Financial Studies $19,531-559$.

Wooldridge, J., 2009. On estimating firm-level production functions using proxy variables to control for unobservables. Economics Letters 104, 112-114. 


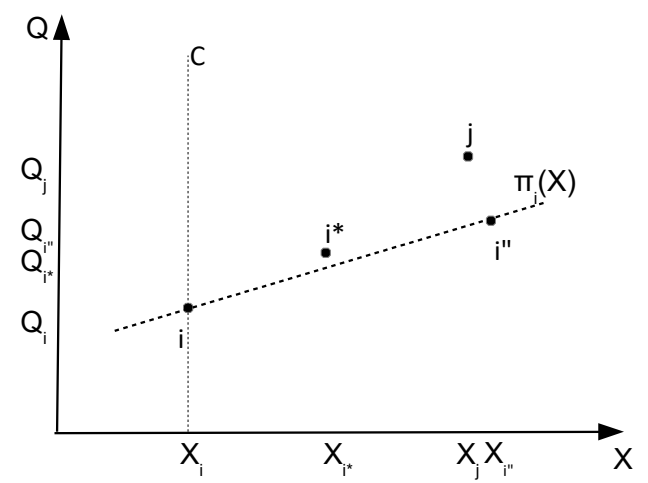

(a) Four firm observations

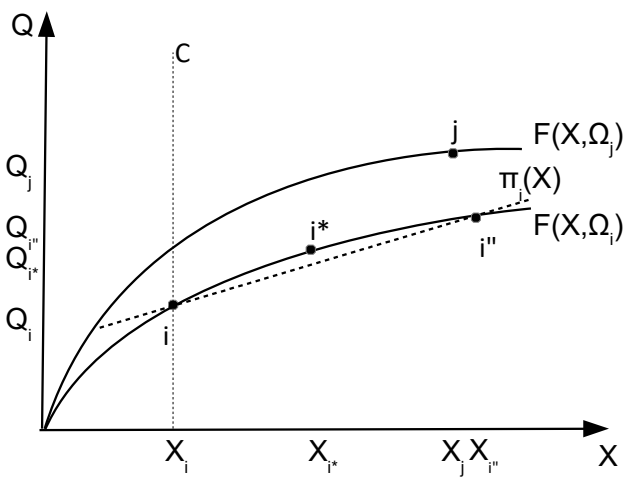

(b) Identifying $\mathrm{C}$ and $F(\mathbf{X}, \Omega)$

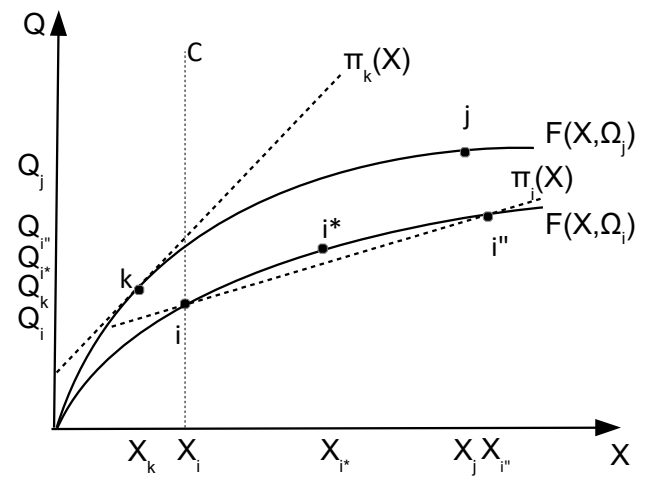

(c) Recovering $\Omega$ and FC

Figure 1: Identification of financial constraints with unobserved heterogeneity in productivity 
Figure 2: Financial constraints over time

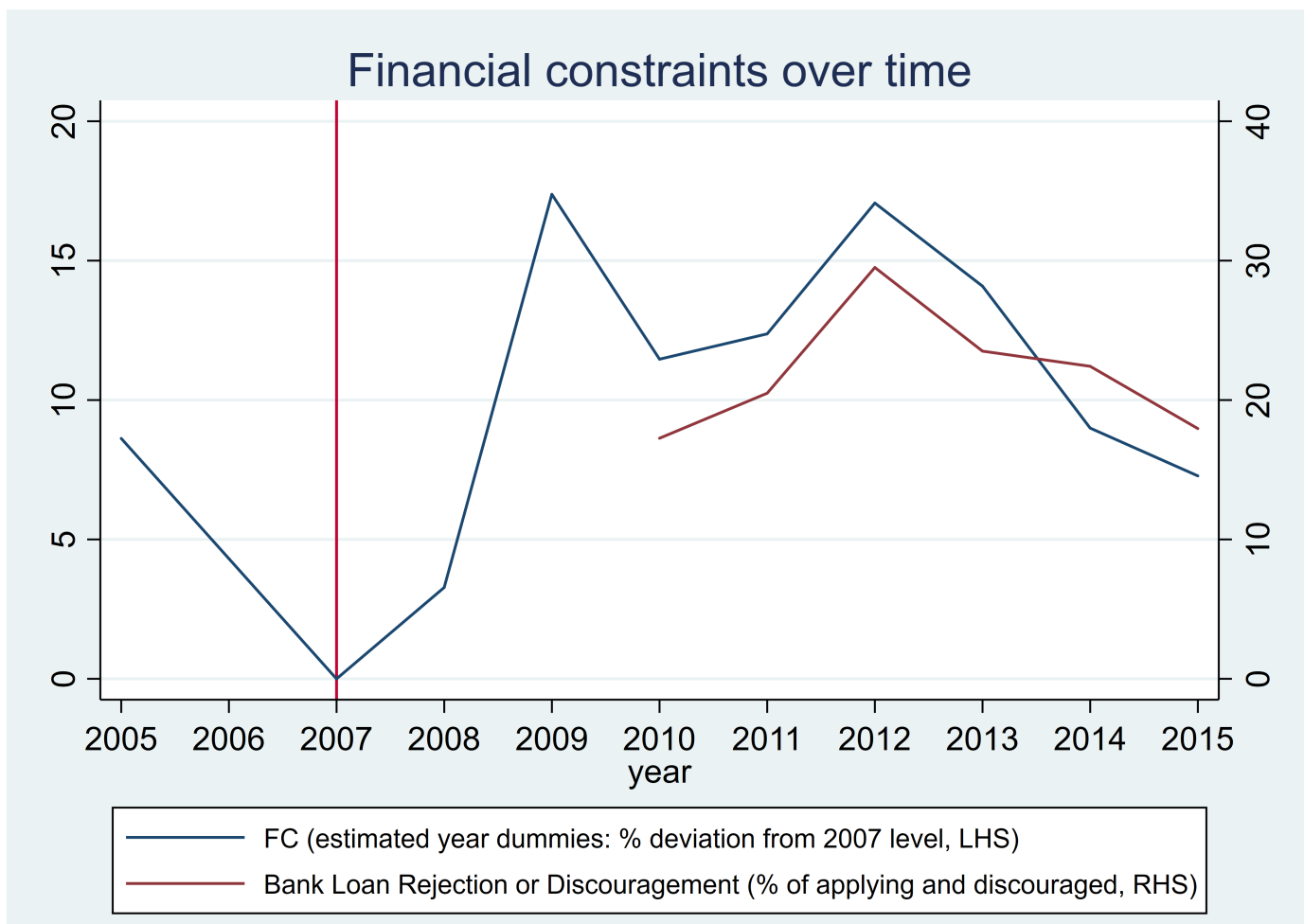


Figure 3: Financial constraints by country over time

\section{Financial constraints over time}

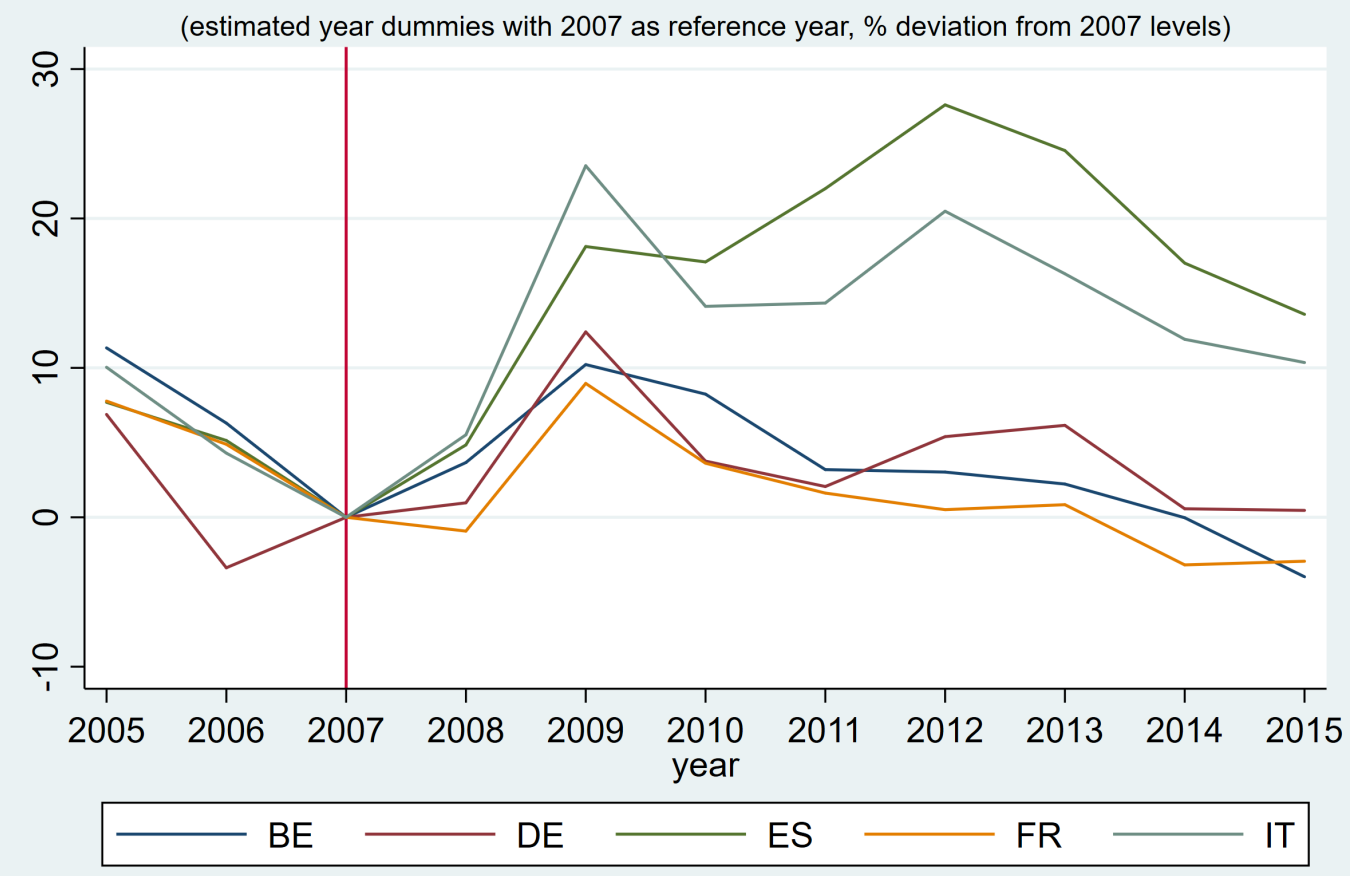


Figure 4: Our measure and popular measures of financial constraints over time

\section{Financial constraints over time}

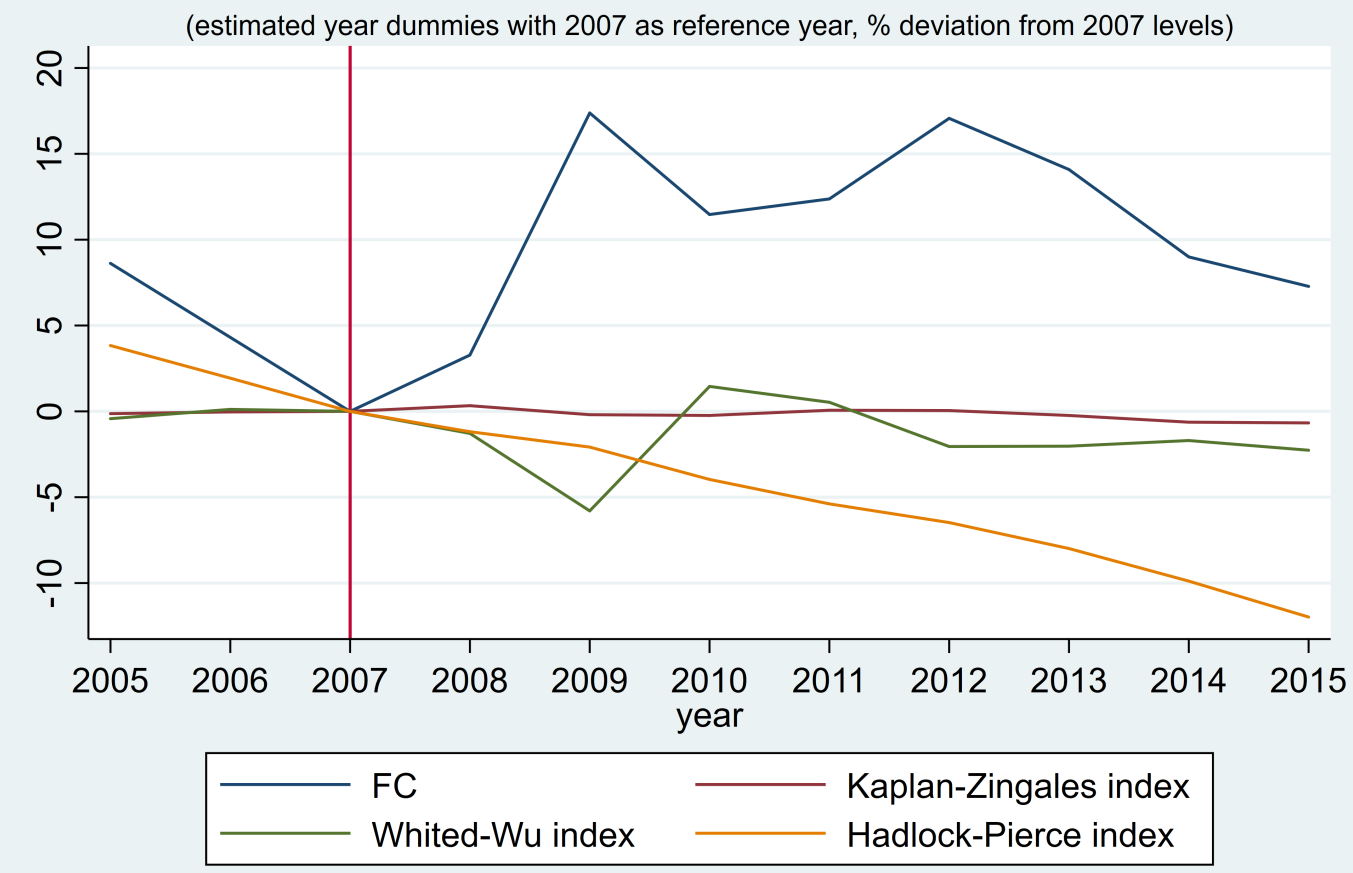




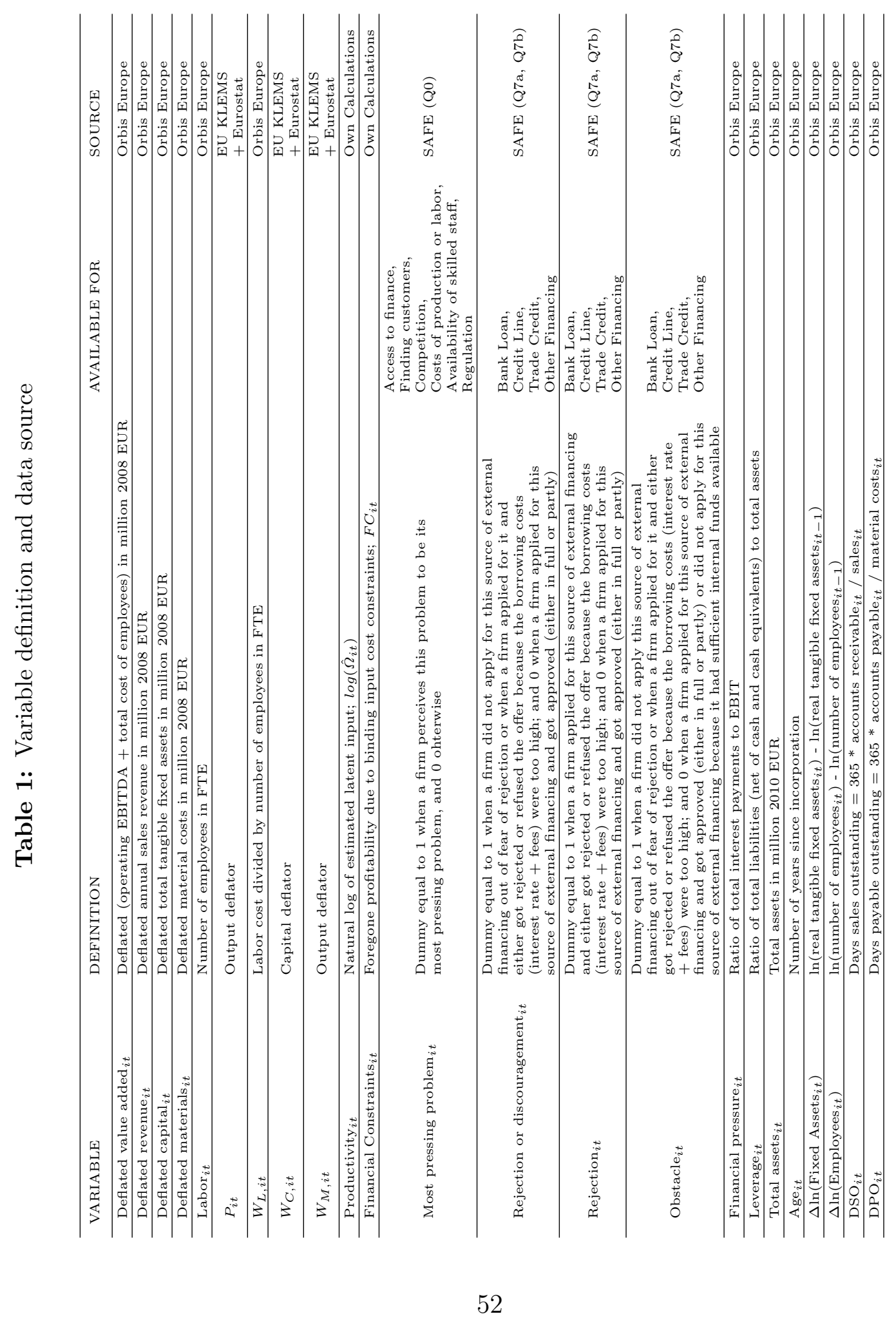


Table 2: Observations included

\begin{tabular}{lcc}
\hline Country & Firm-year observations & Number of firms \\
\hline BE & 16,906 & 4,407 \\
DE & 65,924 & 14,240 \\
ES & 184,424 & 38,028 \\
FR & 118,868 & 28,253 \\
IT & 342,520 & 64,463 \\
\hline Total & 728,642 & 149,391 \\
\hline
\end{tabular}


Table 3: Summary statistics

This table shows summary statistics of all variables used in this paper. Panel A shows all variables used to estimate the production function of the firms and to identify financial constraints. Panel B shows summary statistics for our new measure of financial constraints and three measures that are derived from the firm's replies to the SAFE survey. Panel C shows summary statistics of variables that are typically believed to be related to financial constraints either as determinant or as affected outcome variable.

\begin{tabular}{|c|c|c|c|c|c|}
\hline & Obs. & Mean & St.Dev. & $\mathrm{p} 5$ & p95 \\
\hline \multicolumn{6}{|l|}{ Panel A } \\
\hline$P_{i t}^{V A}$ & 728,642 & 1.013 & 0.053 & 0.918 & 1.099 \\
\hline 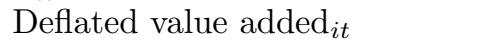 & 728,642 & 5.372 & 114.8 & 0.160 & 13.24 \\
\hline$W_{i t}^{L}$ & 728,642 & 0.036 & 0.013 & 0.018 & 0.059 \\
\hline Labor $_{i t}$ & 728,642 & 76.32 & 1,177 & 5 & 208.0 \\
\hline$W_{i t}^{C}$ & 728,642 & 1.002 & 0.022 & 0.953 & 1.025 \\
\hline Deflated capital $_{i t}$ & 728,642 & 3.897 & 90.80 & 0.017 & 9.715 \\
\hline Productivity $_{i t}$ & 728,642 & 3.942 & 30.22 & 0.177 & 10.78 \\
\hline \multicolumn{6}{|l|}{ Panel B } \\
\hline Financial constraints $_{i t}$ & 728,642 & 0.552 & 0.521 & 0.000 & 1.741 \\
\hline \multicolumn{6}{|l|}{ Most pressing problem: } \\
\hline 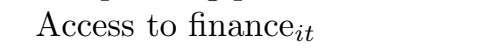 & 6,582 & 0.124 & 0.330 & 0 & 1 \\
\hline Finding customers $i t$ & 6,582 & 0.258 & 0.438 & 0 & 1 \\
\hline Competition $_{i t}$ & 6,582 & 0.143 & 0.350 & 0 & 1 \\
\hline Costs of production or labor ${ }_{i t}$ & 6,582 & 0.203 & 0.402 & 0 & 1 \\
\hline Availability of skilled staff $_{i t}$ & 6,582 & 0.105 & 0.307 & 0 & 1 \\
\hline Regulation $_{i t}$ & 6,582 & 0.079 & 0.270 & 0 & 1 \\
\hline \multicolumn{6}{|l|}{ Rejection or discouragement: } \\
\hline Bank $\operatorname{loan}_{i t}$ & 2,315 & 0.246 & 0.431 & 0 & 1 \\
\hline Credit line $i t$ & 1,710 & 0.285 & 0.452 & 0 & 1 \\
\hline Trade credit $_{i t}$ & 1,684 & 0.213 & 0.409 & 0 & 1 \\
\hline Other financing $_{i t}$ & 899 & 0.248 & 0.432 & 0 & 1 \\
\hline \multicolumn{6}{|l|}{ Panel C } \\
\hline Financial pressure $_{i t}$ & 728,642 & 0.512 & 0.644 & 0.004 & 1.259 \\
\hline Leverage $_{i t}$ & 728,642 & 0.553 & 0.305 & -0.019 & 0.954 \\
\hline Age $_{i t}$ & 728,642 & 23.18 & 17.56 & 4 & 53 \\
\hline Total Assets $_{i t}$ & 728,642 & 9.427 & 29.82 & 0.294 & 36.33 \\
\hline \multicolumn{6}{|l|}{ Panel D } \\
\hline $\mathrm{DSO}_{i t}-\mathrm{DPO}_{i t}$ & 488,099 & -61.76 & 127.1 & -324.5 & 84.65 \\
\hline$\left(\mathrm{AR}_{i t}-\mathrm{AP}_{i t}\right) / \mathrm{TA}_{i t}$ & 488,099 & 12.31 & 18.21 & -16.34 & 44.48 \\
\hline$\Delta \ln \left(\operatorname{Cash}_{i t}\right)$ & 488,099 & 0.022 & 1.151 & -2.055 & 2.077 \\
\hline $\mathrm{Cash}_{i t} / \mathrm{TA}_{i t}$ & 488,099 & 10.25 & 12.95 & 0.029 & 38.82 \\
\hline$\Delta \ln ($ Fixed Assets $i t)$ & 488,099 & -0.011 & 0.228 & -0.355 & 0.476 \\
\hline$\Delta \ln \left(\right.$ Employees $\left._{i t}\right)$ & 488,099 & 0.005 & 0.100 & -0.163 & 0.182 \\
\hline
\end{tabular}


Table 4: The $F C$ measure and firm characteristics

This table shows the average value of our new measure of financial constraints. In addition to results for the whole sample, we show the results per country, for three firm size groups and for three age groups. Micro/Small includes firm-year observations with less than 50 employees, Medium includes firm-year observations with more than 50 but less than 250 employees, and Large those with more than 250 employees. Young includes firm-year observations less than than 10 years after start-up, Mature includes firm-year observations between 10 and 25 years after start-up, and Old those more than 25 years after start-up. ${ }^{* * *}, * *$ and ${ }^{*}$ denote $\mathrm{p}<0.01$, $\mathrm{p}<0.05$ and $\mathrm{p}<0.1$ respectively for a two-sample t-test in which the respective group (i.e., a column-row pair) is compared to the column-row pair to the right.

\begin{tabular}{c|c|ccc|ccc}
\hline & All & Micro/Small & Medium & Large & Young & Mature & Old \\
\hline All & 0.552 & $0.596^{* * *}$ & $0.390^{* * *}$ & 0.471 & $0.643^{* * *}$ & $0.556^{* * *}$ & 0.477 \\
\hline BE & 0.384 & $0.402^{* * *}$ & $0.351^{* * *}$ & 0.323 & $0.428^{* * *}$ & $0.384^{* *}$ & 0.371 \\
DE & 0.373 & $0.465^{* * *}$ & $0.327^{* * *}$ & 0.461 & $0.413^{* * *}$ & $0.386^{* * *}$ & 0.350 \\
FR & 0.599 & $0.617^{* * *}$ & $0.464^{* * *}$ & 0.501 & $0.668^{* * *}$ & $0.601^{* * *}$ & 0.524 \\
ES & 0.595 & $0.648^{* * *}$ & $0.393^{* * *}$ & 0.537 & $0.729^{* * *}$ & $0.623^{* * *}$ & 0.493 \\
IT & 0.555 & $0.580^{* * *}$ & 0.421 & 0.442 & $0.642^{* * *}$ & $0.538^{* * *}$ & 0.497 \\
\hline
\end{tabular}




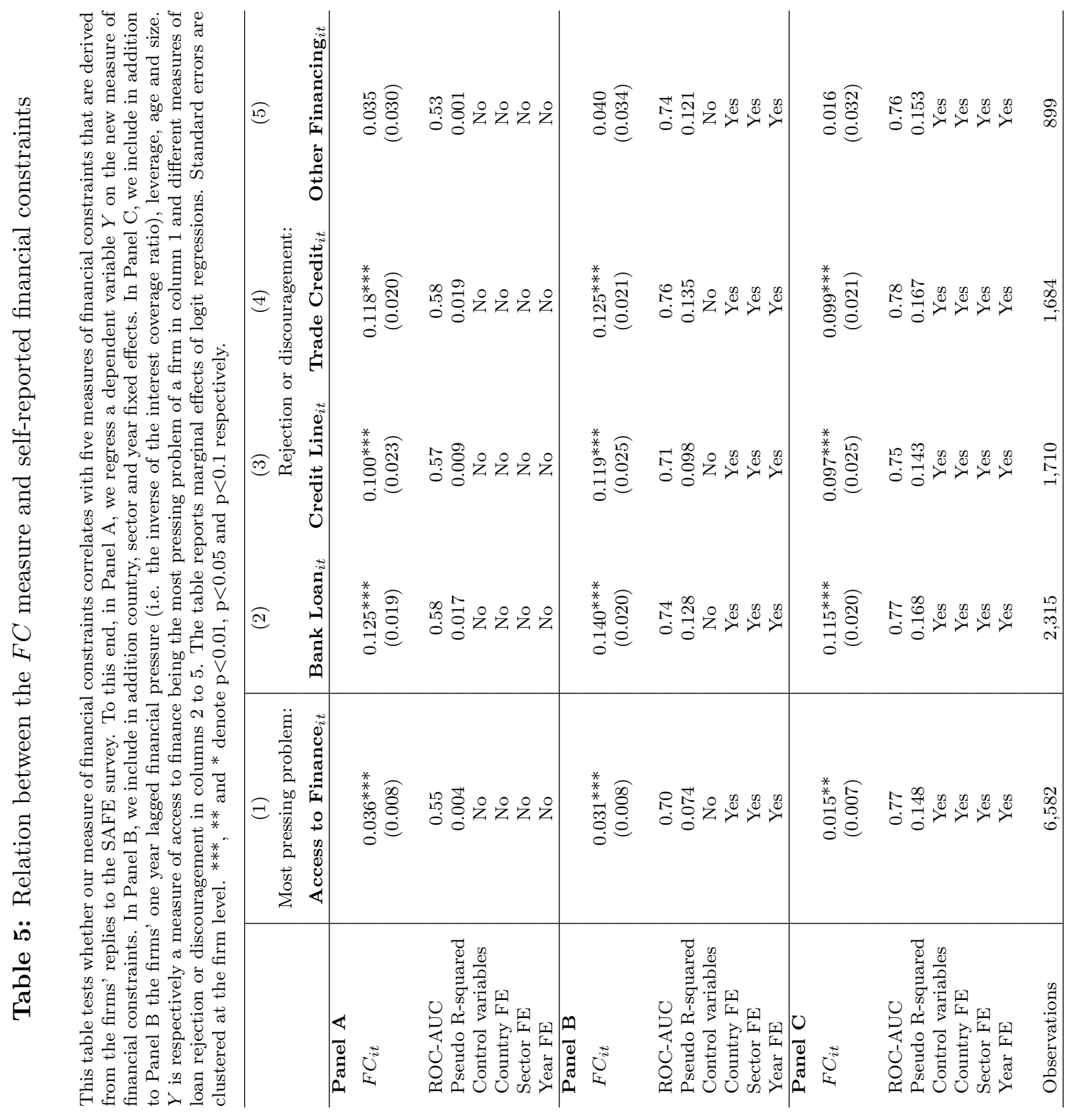




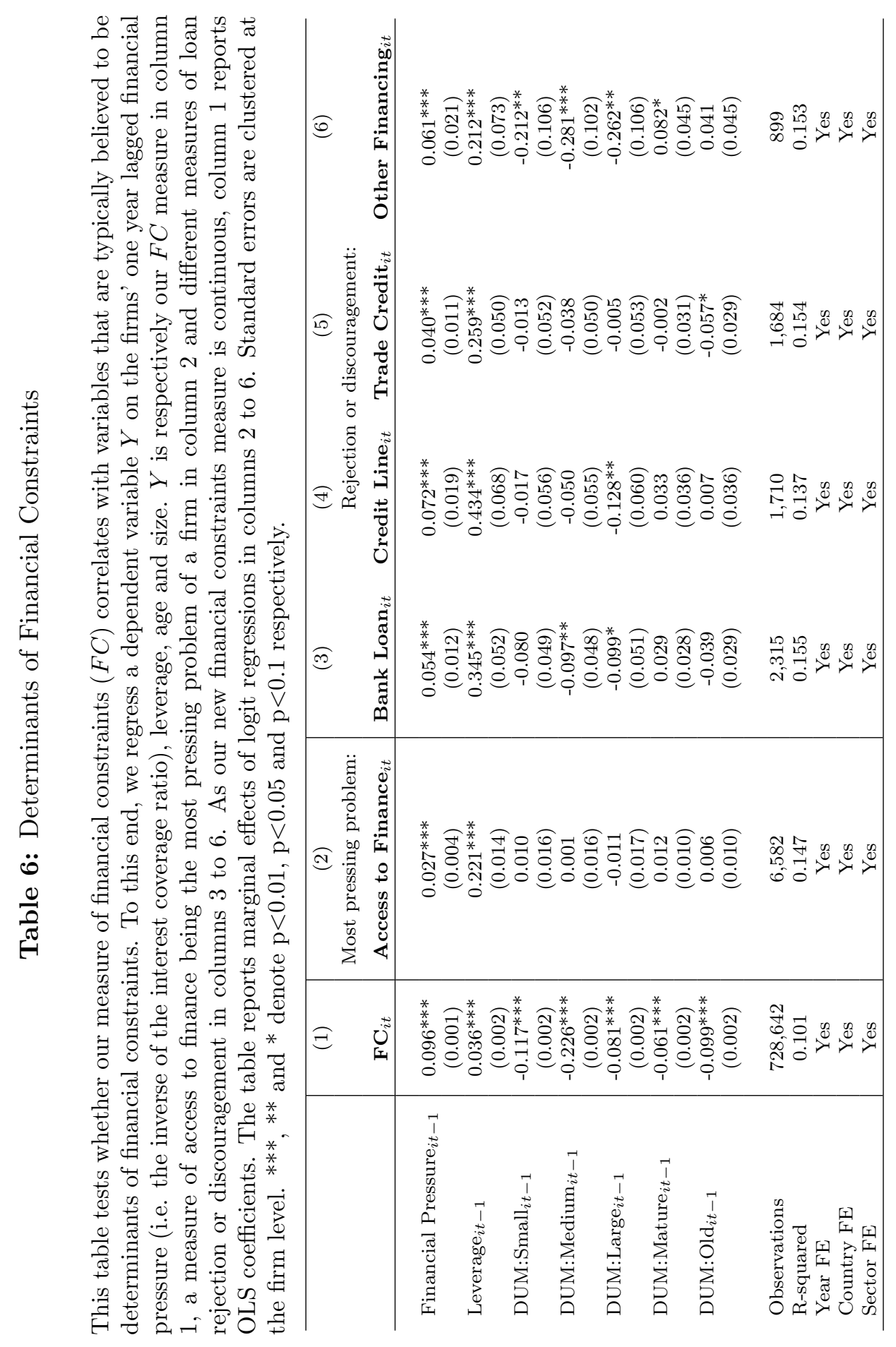


Table 8: Financial constraints and price-setting power

This table shows the correlation between our measure of financial constraints and self-reported financial constraints for several subsamples for which we believe the firms to have negligible price-setting power. For this, we exclude observations in the top quartile of the distribution of the following measures of pricing power: the firm's domestic market share (nace 4-digit level), the firm's market share (nace 4-digit level, all 5 countries), the Herfindahl-Hirschman Index (HHI) for each domestic nace 4-digit sector, the HHI for each nace 4-digit sector (all 5 countries). The self-reported measure of financial constraints that we look at is the rejection or discouragement of bank loans. The Wald-test in columns 2 to 5 tests whether the coefficient in the respective subsample is statistically different from the coefficient in the full sample (p-values shown). Again, Panel A shows the results without fixed effects or control variables. In Panel B, we include in country, sector and year fixed effects. In Panel C, we include in addition to Panel B the firms' one year lagged financial pressure (i.e. the inverse of the interest coverage ratio), leverage, age and size. The table reports marginal effects of logit regressions. Standard errors are clustered at the firm level. ${ }^{* * *},{ }^{* *}$ and ${ }^{*}$ denote $\mathrm{p}<0.01, \mathrm{p}<0.05$ and $\mathrm{p}<0.1$ respectively.

\begin{tabular}{|c|c|c|c|c|c|}
\hline & $\begin{array}{c}\text { (1) } \\
\text { full sample }\end{array}$ & $\begin{array}{c}\text { Rejection } \\
(2) \\
\text { country level } \\
\text { sectoral } \mathrm{MS}<\mathrm{Q} 4 \\
\end{array}$ & $\begin{array}{c}\text { or discouragement } \\
(3) \\
\text { full sample } \\
\text { sectoral } \mathrm{MS}<\mathrm{Q} 4 \\
\end{array}$ & $\begin{array}{c}\text { Bank } \operatorname{Loan}_{i t} \\
(4) \\
\text { country level } \\
\text { sectoral } \mathrm{HHI}<\mathrm{Q} 4 \\
\end{array}$ & $\begin{array}{c}(5) \\
\text { full sample } \\
\text { sectoral } \mathrm{HHI}<\mathrm{Q} 4\end{array}$ \\
\hline \multicolumn{6}{|l|}{ Panel A } \\
\hline$F C_{i t}$ & $\begin{array}{c}0.125^{* * *} \\
(0.019)\end{array}$ & $\begin{array}{c}0.123^{* * *} \\
(0.023)\end{array}$ & $\begin{array}{c}0.129^{* * *} \\
(0.023)\end{array}$ & $\begin{array}{c}0.125^{* * *} \\
(0.023)\end{array}$ & $\begin{array}{c}0.107^{* * *} \\
(0.021)\end{array}$ \\
\hline $\begin{array}{l}\text { Wald-test (p-value) } \\
\text { ROC-AUC } \\
\text { Pseudo R-squared } \\
\text { Control variables } \\
\text { Country FE } \\
\text { Sector FE } \\
\text { Year FE }\end{array}$ & $\begin{array}{c}0.58 \\
0.017 \\
\text { No } \\
\text { No } \\
\text { No } \\
\text { No }\end{array}$ & $\begin{array}{c}0.93 \\
0.57 \\
0.016 \\
\text { No } \\
\text { No } \\
\text { No } \\
\text { No }\end{array}$ & $\begin{array}{c}0.88 \\
0.58 \\
0.017 \\
\text { No } \\
\text { No } \\
\text { No } \\
\text { No }\end{array}$ & $\begin{array}{c}0.99 \\
0.58 \\
0.016 \\
\text { No } \\
\text { No } \\
\text { No } \\
\text { No }\end{array}$ & $\begin{array}{c}0.40 \\
0.56 \\
0.013 \\
\text { No } \\
\text { No } \\
\text { No } \\
\text { No }\end{array}$ \\
\hline \multicolumn{6}{|l|}{ Panel B } \\
\hline$F C_{i t}$ & $\begin{array}{c}0.140 * * * \\
(0.020)\end{array}$ & $\begin{array}{c}0.126^{* * *} \\
(0.026)\end{array}$ & $\begin{array}{c}0.131^{* * *} \\
(0.026)\end{array}$ & $\begin{array}{c}0.130 * * * \\
(0.025)\end{array}$ & $\begin{array}{c}0.117^{* * *} \\
(0.024)\end{array}$ \\
\hline $\begin{array}{l}\text { Wald-test (p-value) } \\
\text { ROC-AUC } \\
\text { Pseudo R-squared } \\
\text { Control variables } \\
\text { Country FE } \\
\text { Sector FE } \\
\text { Year FE }\end{array}$ & $\begin{array}{c}0.74 \\
0.128 \\
\text { No } \\
\text { Yes } \\
\text { Yes } \\
\text { Yes }\end{array}$ & $\begin{array}{l}0.58 \\
0.74 \\
0.138 \\
\text { No } \\
\text { Yes } \\
\text { Yes } \\
\text { Yes }\end{array}$ & $\begin{array}{c}0.72 \\
0.74 \\
0.133 \\
\text { No } \\
\text { Yes } \\
\text { Yes } \\
\text { Yes }\end{array}$ & $\begin{array}{c}0.68 \\
0.73 \\
0.119 \\
\text { No } \\
\text { Yes } \\
\text { Yes } \\
\text { Yes }\end{array}$ & $\begin{array}{c}0.34 \\
0.74 \\
0.127 \\
\text { No } \\
\text { Yes } \\
\text { Yes } \\
\text { Yes }\end{array}$ \\
\hline \multicolumn{6}{|l|}{ PanelC } \\
\hline$F C_{i t}$ & $\begin{array}{c}0.115^{* * *} \\
(0.020)\end{array}$ & $\begin{array}{c}0.101^{* * *} \\
(0.026)\end{array}$ & $\begin{array}{c}0.109^{* * *} \\
(0.026)\end{array}$ & $\begin{array}{c}0.099 * * * \\
(0.025)\end{array}$ & $\begin{array}{c}0.090^{* * *} \\
(0.023)\end{array}$ \\
\hline Wald-test (p-value) & & 0.59 & 0.81 & 0.51 & 0.26 \\
\hline ROC-AUC & 0.77 & 0.79 & 0.78 & 0.77 & 0.78 \\
\hline Pseudo R-squared & 0.168 & 0.187 & 0.183 & 0.163 & 0.172 \\
\hline Control variables & Yes & Yes & Yes & Yes & Yes \\
\hline Country FE & Yes & Yes & Yes & Yes & Yes \\
\hline Sector FE & Yes & Yes & Yes & Yes & Yes \\
\hline Year FE & Yes & Yes & Yes & Yes & Yes \\
\hline Observations & 2,315 & 1,638 & 1,644 & 1,781 & 1,779 \\
\hline
\end{tabular}




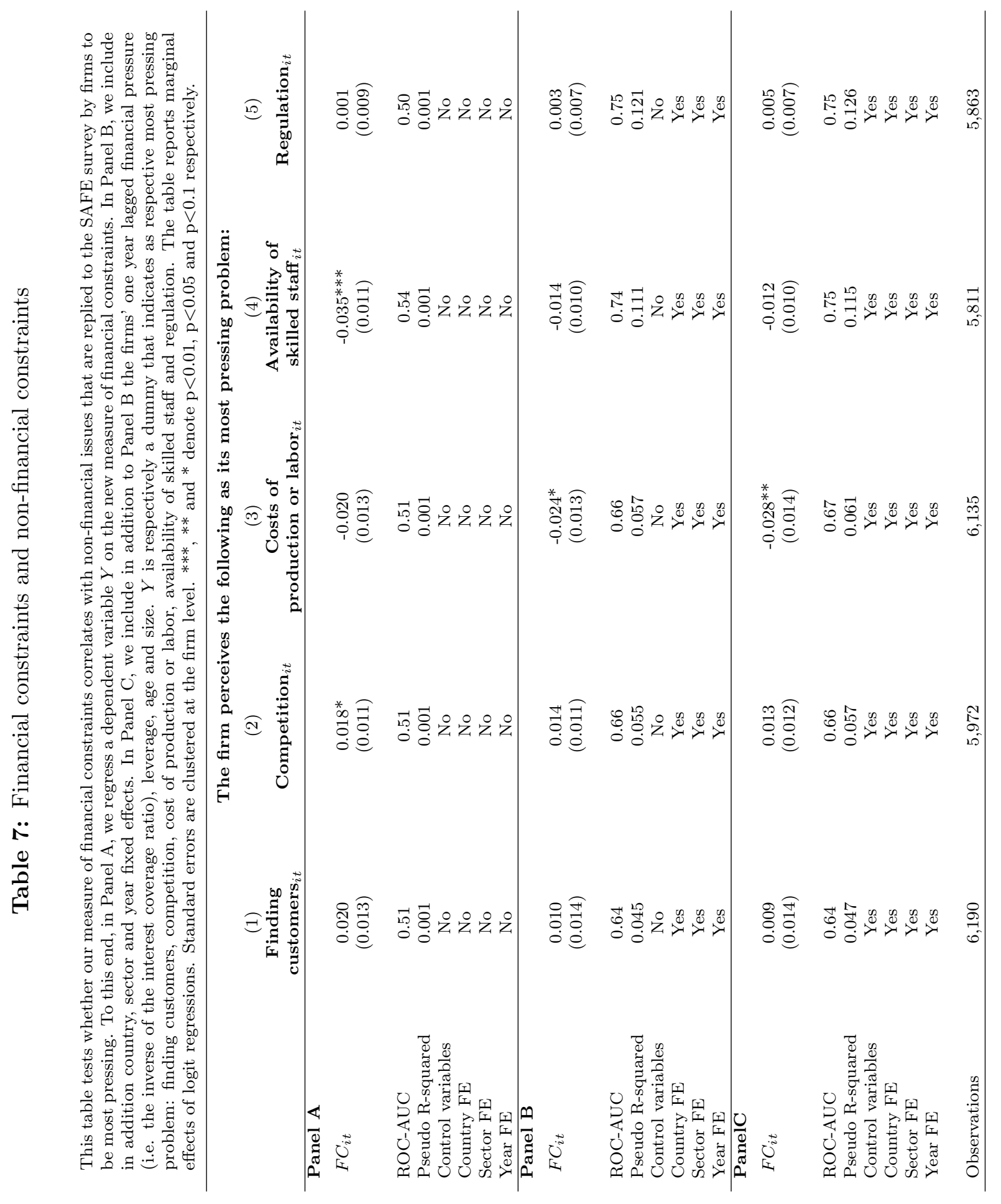




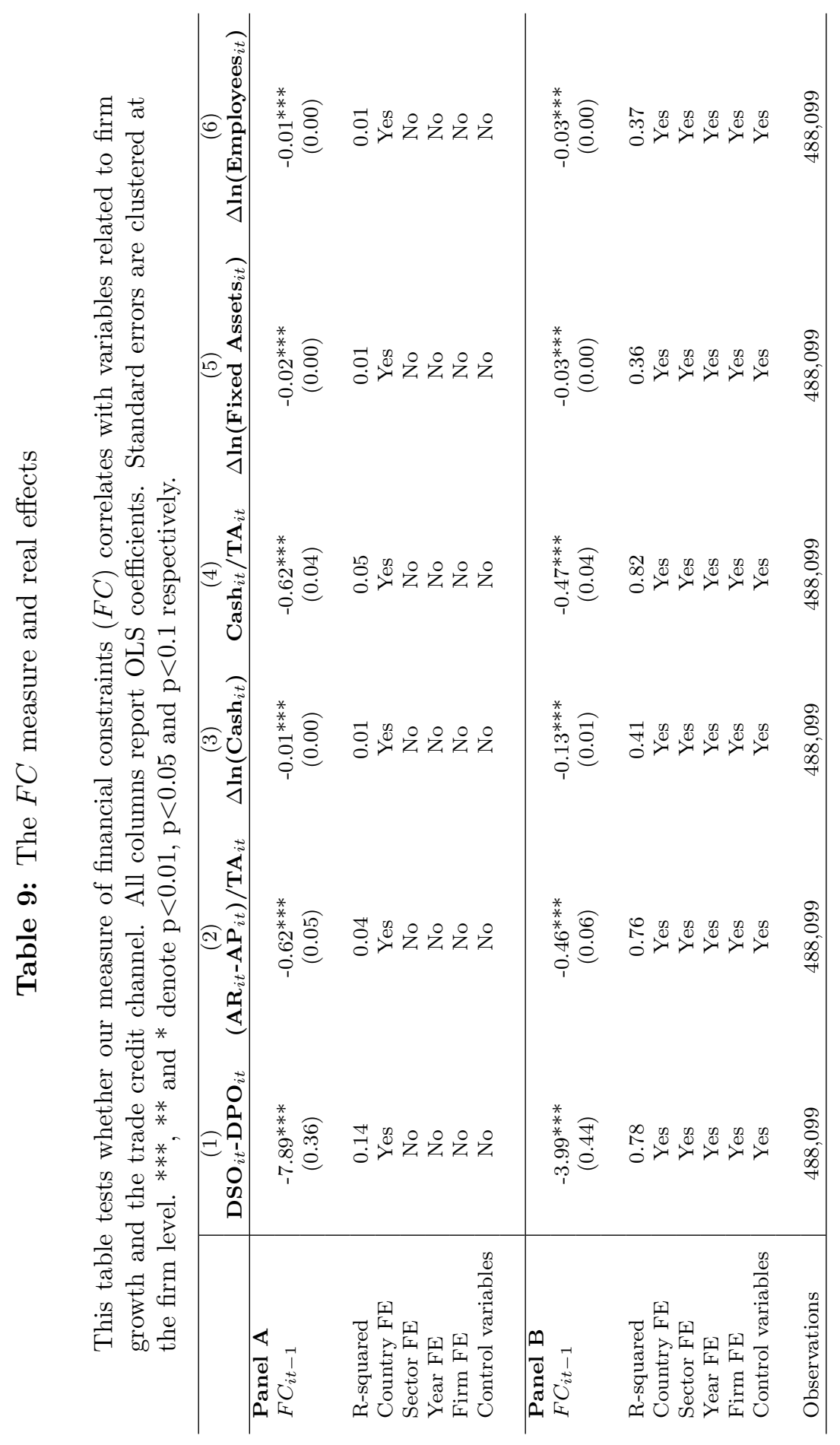


Table 10: Our FC measure and popular financial constraints indices: correlation table

This table shows the Spearman correlation between our measure of financial constraints $\left(F C_{i t}\right)$ and the three most widely used indices of financial constraints (the Kaplan-Zingales $i t$ index, the Whited-Wu $\mathrm{Wu}_{i t}$ index, and the Hadlock-Pierce ${ }_{i t}$ index). In Panel A we show the correlation using the private firms in our sample. For these firms the KZ index is computed without taking Tobin's $\mathrm{Q}$ and dividend information into account; the WW index is computed without taking dividend information into account; and the HP index is computed using age since start-up (instead of since IPO). In Panel B we show the correlation using the public firms in our sample.

\begin{tabular}{lccc}
\hline Panel A $(\mathrm{n}=653,419)$ & $F C_{i t}$ & Kaplan-Zingales $_{i t}$ & Whited-Wu $_{i t}$ \\
\hline Kaplan-Zingales & & & \\
Whited-Wu $_{i t}$ & 0.067 & & \\
Hadlock-Pierce $_{i t}$ & 0.314 & 0.006 & \\
& 0.257 & -0.019 & 0.777 \\
\hline Panel B $(\mathrm{n}=1,902)$ & $F C_{i t}$ & Kaplan-Zingales $_{i t}$ & Whited-Wu $_{i t}$ \\
\hline & & & \\
Kaplan-Zingales $_{i t}$ & 0.046 & & \\
Whited-Wu $_{i t}$ & 0.266 & 0.220 & \\
Hadlock-Pierce $_{i t}$ & 0.134 & 0.026 & 0.673 \\
& & & \\
\hline
\end{tabular}




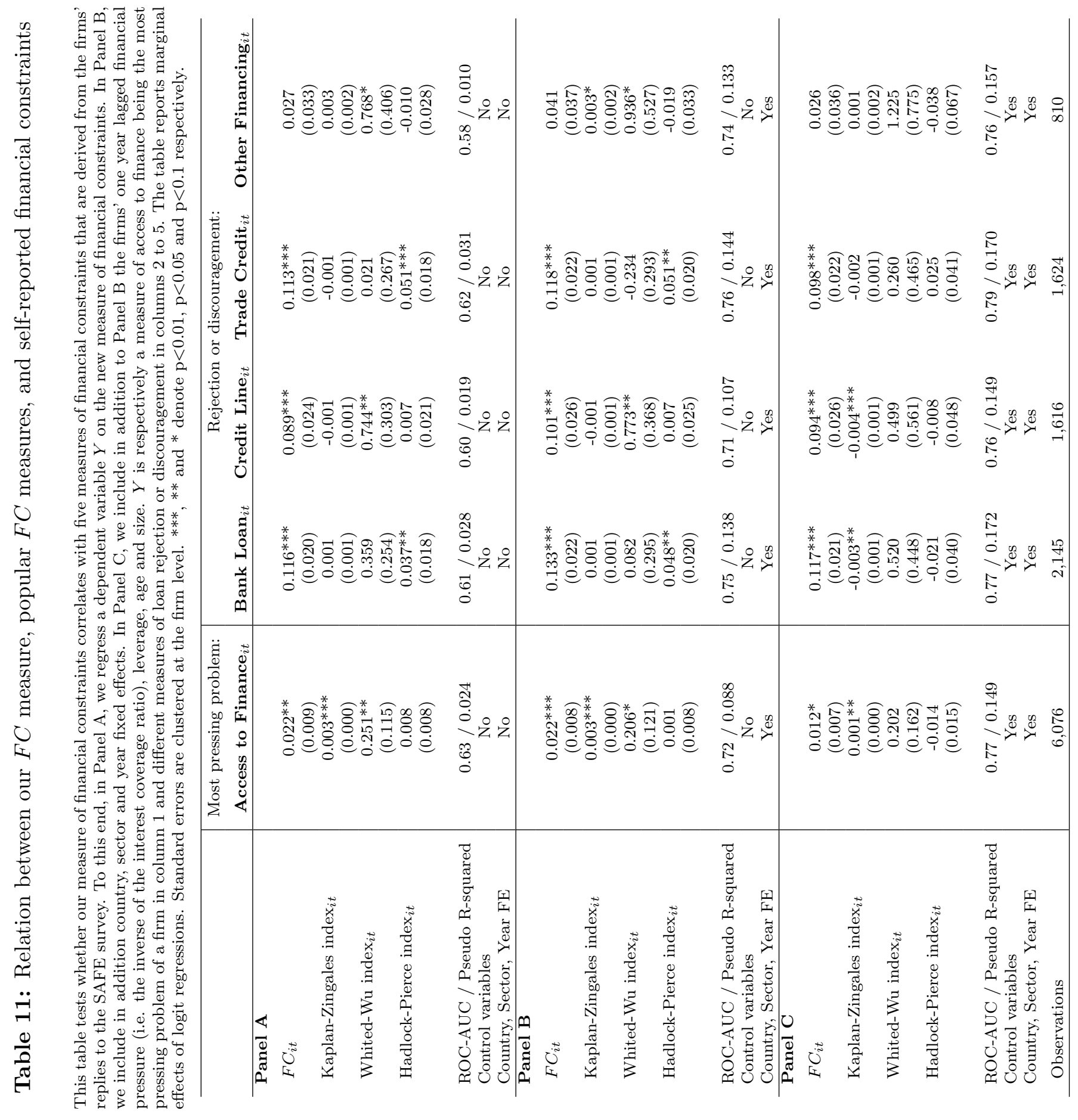


Table 12: Our FC measure and the components of popular financial constraints indices

This table shows the outcome of an OLS regression where the dependent variable is our measure of financial constraints $\left(F C_{i t}\right)$ and the independent variables are, respectively, the index components of the three most widely used indices of financial constraints (the Kaplan-Zingales ${ }_{i t}$ index in Panel A, the Whited-Wu $\mathrm{Wu}_{i t}$ index in Panel B, and the Hadlock-Pierce $i t$ index in Panel C). Columns 1 and 2 show the results using only the private firms in our sample. Columns 3 and 4 show the results using only the public firms in our sample. Columns 1 and 3 do not include any fixed effects, while Columns 2 and 4 include country, sector, year, and firm fixed effects. Standard errors are clustered at the firm level. ${ }^{* *},{ }^{* *}$ and ${ }^{*}$ denote $\mathrm{p}<0.01, \mathrm{p}<0.05$ and $\mathrm{p}<0.1$ respectively.

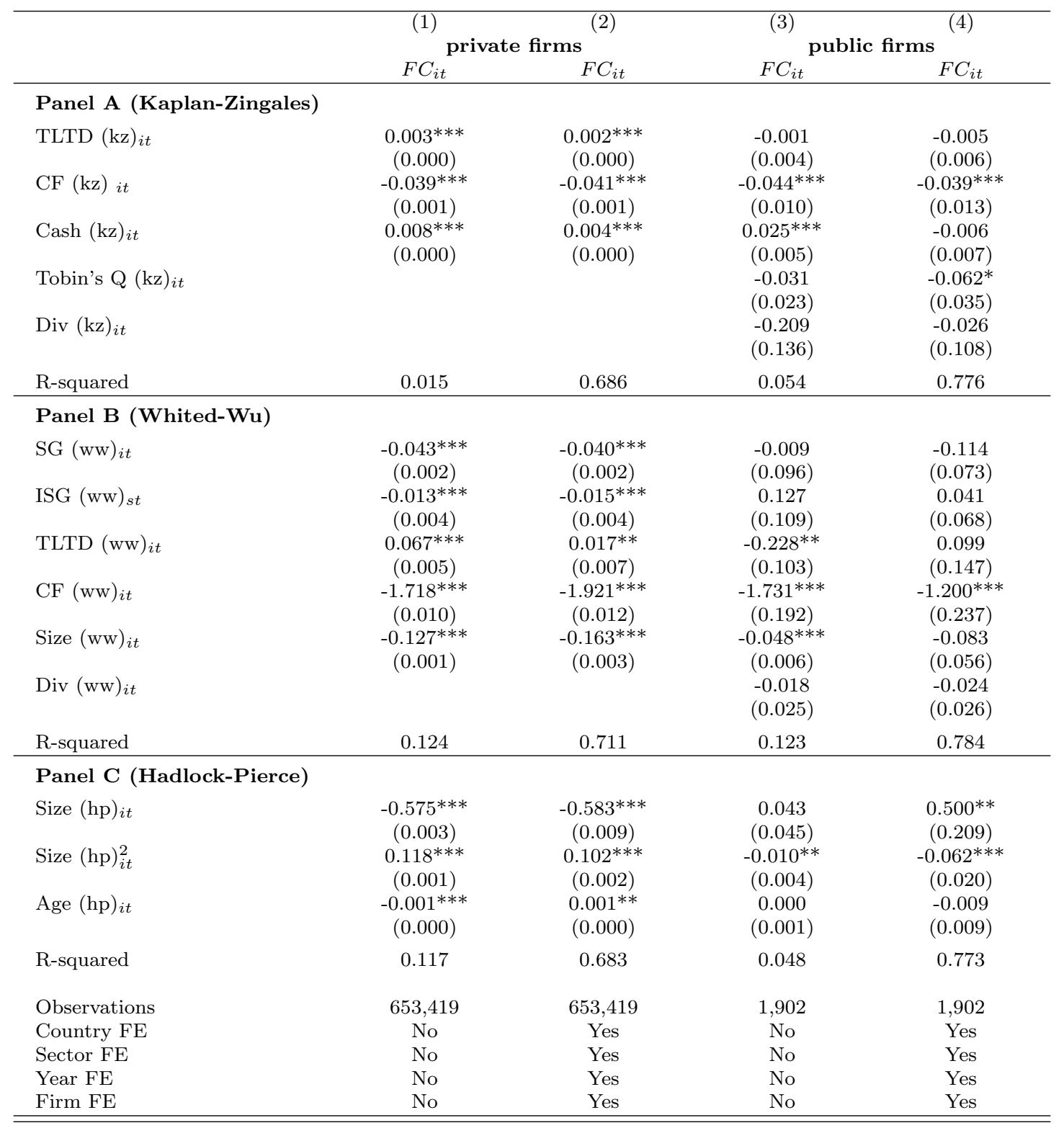




\section{Appendix A: Data construction and estimation}

To avoid effects of extreme outliers and extreme noise in the whole dataset that is described in Section 3, we limit the sample to observations of firms with at least five employees. We limit the sample to firms with a book year equal to 12 months. We removed the highest and lowest percentile (at country-sector-firm size level) of the level and growth rates, for our output measure, our observed inputs, the price of labor, observed profit, observed costs, observed profitability, share of respectively labor and capital in observed costs, labor productivity, capital productivity (with capital defined as tangible fixed assets). We excluded labor from the cleaning on levels. We also removed clear erroneous reporting by limiting the sample to deflated input-output observations with values over 1,000 euro and labor price (i.e. annual cost of 1 FTE) with values over 10,000 euro.

To obtain homogeneous sets of firm observations as a basis of the $F C$ estimation, we compare profitability only within countries in narrowly defined industry and firm size classes. We consider nace 4-digit industries (nace rev. 2 classification) and 7 firm size groups, based on the European Commission classification of firm size categories. We consider (1) very large firms (total assets more than 43 million euro, and labor in FTE of more than 1000), (2) large firms (total assets more than 43 million euro, and labor lower than 1000), (3) Medium sized firms-category 1 (labor in FTE between 100 and 250 and total assets lower than 43 million euro), (4) Medium sized firmscategory 2 (labor in FTE between 50 and 100 and total assets lower than 43 million euro), (5) Small firms (labor in FTE lower than 50 and total assets lower than 10 million euro). (6) Very small firms (small firms with labor in FTE lower than 25), (7) Micro firms (labor in FTE lower than 10 and total assets not exceeding 2 million euro).

We only estimate $F C_{i t}$ (i.e. foregone profitability for firm $i$ in year $t$ ) when the 
number of observations in a country-sector-firm size group is equal to or more than 50. This selection criterion yields 3,143 country-sector-firm size groups with on average 986 comparison observations. We ran separate linear programs for all groups. To account for the fact that inputs are not perfectly flexible, we limit the set of comparison partners for every evaluated firm to other firms with similar labor and capital cost shares. In particular, only firms with labor and capital cost shares higher than 0.5 and lower than 1.5 times the respective cost shares of the firm in question are considered as potential comparison partners. As explained in Section 2.1, we further robustify our measure to influences from moderate adjustment costs, random noise and deviations from profit maximizing behavior by focusing on testable conditions for close-to rationalization. We do so by using a goodness-of-fit parameter $\theta$ that satisfies $1.01 \leq \theta \leq 1.1$. Cherchye et al. (2018) show in a Monte Carlo analysis that this value for the goodness-of-fit parameter ensures reliable nonparametric recovery of production function parameters and heterogeneity in productivity in settings with considerable noise.

We ran linear programs for the full sample of 923,123 observations of 174,121 firms, but we excluded from our further analysis all firm observations for which the linear program at the country-sector-firm size level was not able to close-to rationalize the data when using a goodness-of-fit parameter $1.01 \leq \theta \leq 1.1$. We interpret that the excluded country-sector-firm size groups have either considerable adjustment costs, noisy data or substantial deviations from profit maximizing behavior. This gives us estimates of $\Omega_{i t}$ and $F C_{i t}$ for 833,767 firm observations pertaining to 162,028 firms, with the average of $\theta$ equaling 1.04. Subsequently, we dropped the top percentile of country-sector-firm size groups in terms of average cost share of the latent input (to remove sectors with unrealistically high latent input levels, due to outliers that were not captured in the cleaning process), we removed observations with no financial data, and we dropped firms with no two consecutive observations (as we use lags as 
independent variables in our regression analyses).

In the final sample used from now on, we have the required balance sheet information for 149,391 firms that are observed on average 4,9 times between 2005 and 2015, implying a total number of 728,642 observations. 3,205 of these firms participated on average 2.1 times in the SAFE survey, implying a total number of 6,582 observations.

In a robustness check, excluding Belgium and Germany, we take deflated sales revenue as output, deflate tangible fixed and the number of employees in full time equivalents (FTE), deflated tangible fixed assets, and deflated materials use as inputs. For the output price, we use the country-industry (nace 2-digit) level producer price deflator. For the input prices, we use respectively the price of labor (which is obtained by dividing labor cost by the number of employees in FTE), the country-industry (nace 2-digit) level deflator for gross fixed capital formation, and a country-industry (nace 2-digit) level deflator for intermediate inputs that is constructed in line with Merlevede et al. (2015). Baseline results using this measure are reported in Table 14 in Appendix B.

\section{Appendix B: Additional tables}




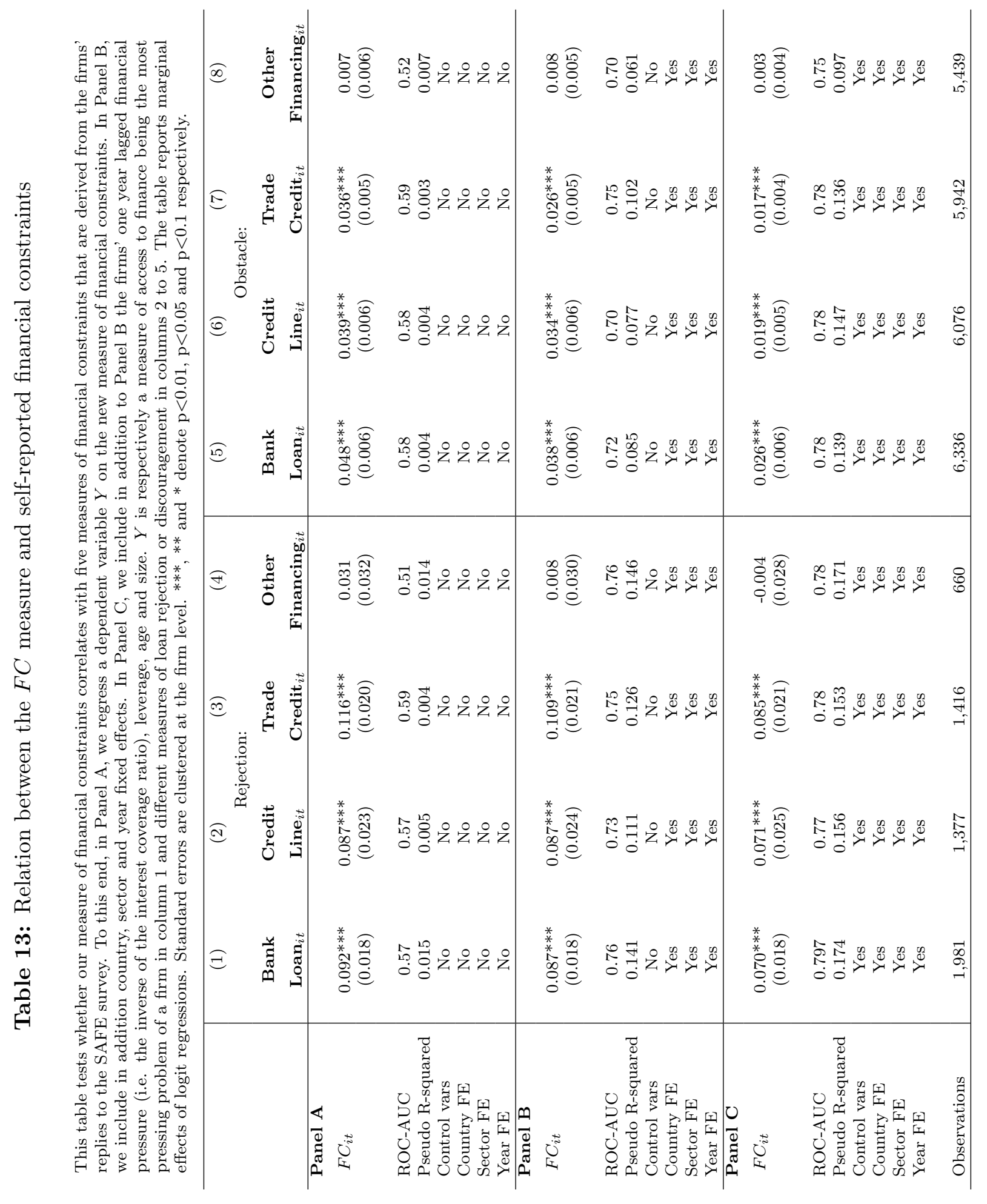




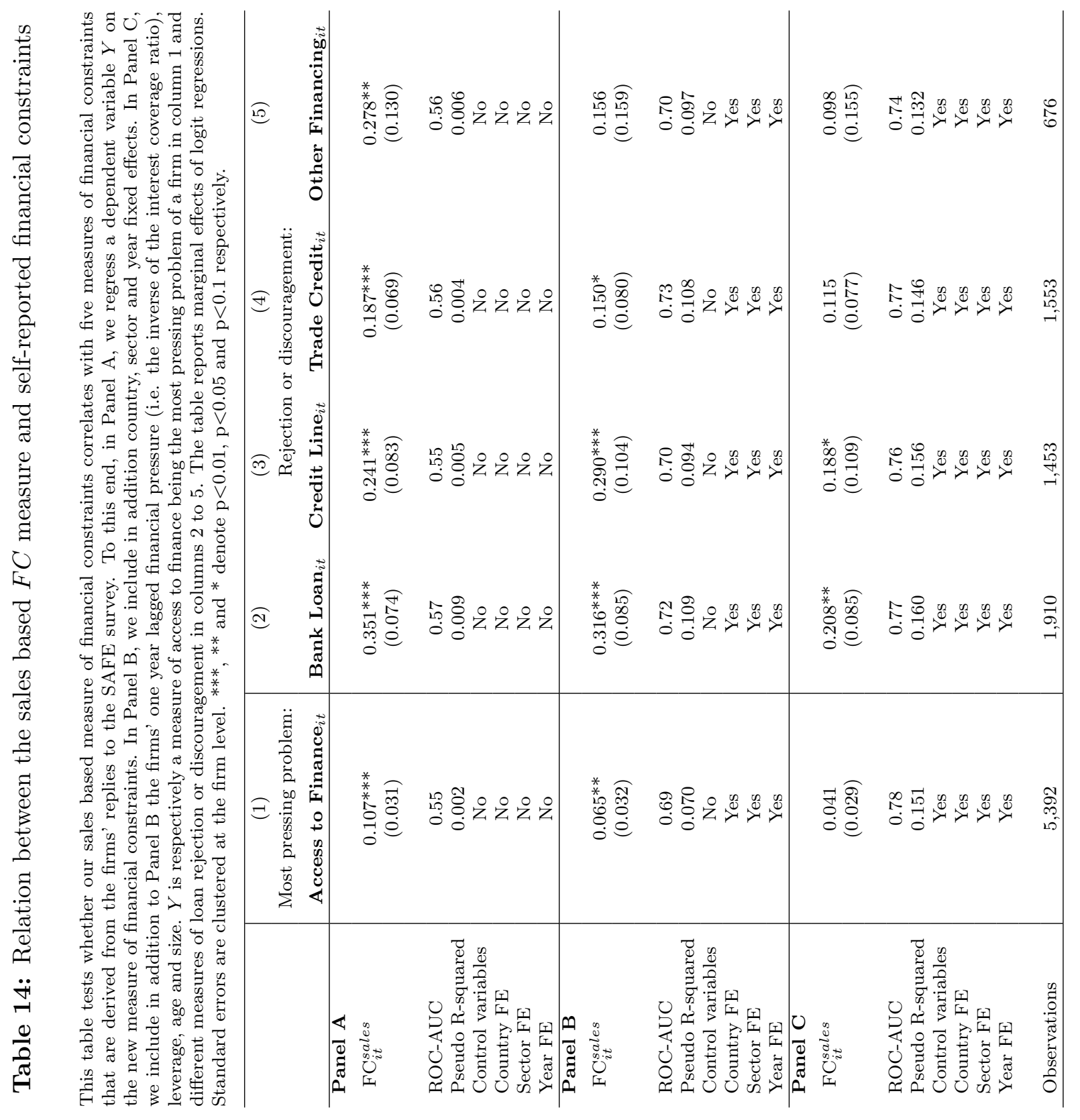

